Radiation Pyrometer. for Gas Turbine Blades

\author{
FINAL REPORT \\ June $1972 \cdot$ October 1973 \\ By \\ David A. Rohy \\ W.A. Compton \\ Prepared Under Contract NA58.28953
}

Solar Division international Harvester Co.

San Diego, Ca 92138

October 1973

For

National Aeronautics and Space Administraticn

George C. Marshall Space Flight Center

Huntsville, Alabama 35812 NAproduced by

INFORAATION SERVICE us Dopartment of Commerco

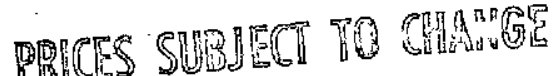

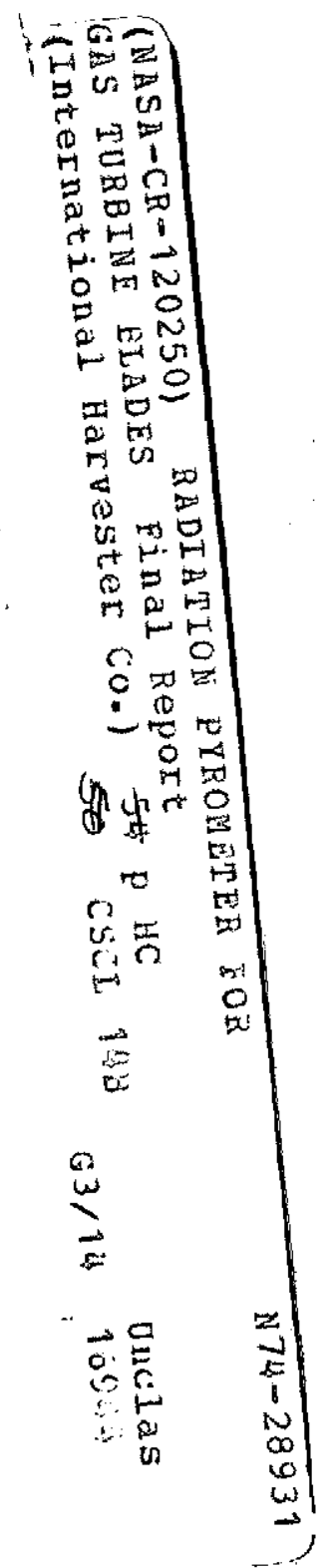




\title{
Radiation Pyrometer for Gas Turbine Blades
}

\author{
FINAL REPORT \\ June 1972 - October 1973
}

By

David A. Rohy

W.A. Compton

Prepared Under Contract NAS8-28953

Solar Division International Harvester Co.

San Diego, Ca 92138

October 1973

\author{
For \\ National Aeronautics and Space Administration \\ George C. Marshall Space Flight Center \\ Huntsville, Alabama 35812
}




\section{CONTENTS}

Section

$\underline{\text { Page }}$

1

INTRODUCTION

1.1 Importance of Turbine Blade Temperature Measurement " 1

1.2 Performance Diagnostic Uses of Turbine Blade Temperature 3

1.2.1 Intelligence Available From a Radiation Pyrometer Sensor 3

1.2.2 Control Parameters

1.2.3 Reliability and Maintainability Parameters 4

1.2.4 Engine Test Analysis and Development 5

1.3 Conclusions. 6

2 PRINCIPLES OF OPERATION

2.1 Turbine Blade Temperature Measurement System $\quad 7$

2.2 Physical Laws Governing Radiation Pyrometry 9

2.3 Radiation Detector

$\begin{array}{ll}2.4 \text { Optical System } & 17\end{array}$

2.5 Lens Type Sensor $\quad 17$

2.6 Aperture Type Sensor Head 20

2.7 Fiber Optics $\quad 20$

2.8 TBTMS Signal Conditioning Unit $\quad 22$

3 SIGNAL PROCESSOR $\quad 25$

3.1 General Description $\quad 25$

3.2 System Operation $\quad 25$

3.3 Detectors $\quad 29$

3.4 Preamplifiers $\quad 30$

3.5 Hybrid Circuits 30

3.6 System Design

3.7 Calibration PRECEDING PAGE BLANK NOT ETAMED 


\section{CONTENTS (Cont)}

Section

Page

4 SENSOR HEAD AND OPTICS 37

4.1 Optical System 37

4.2 Effects of Engine Environment on Data 37

4.3 Description of Sensor Heads 38

4.4 Fiber Optic Cables 43

4.4.1 Fiber Optic Material. 43

4.4.2 Fiber Optic Cable Preparation 44

4.5 Installation 44

5 CALIBRATION TESTS 45 REFERENCES 


\section{LIST OF ILLUSTRATIONS}

Figure

Page

1 Turbine Blade Temperature Measurement System

$2 \quad$ Blackbody Radiance for Several Temperatures 10

3. Spectral Response of Silicon and Radiance from Blackbody and Turbine Gases

4 Detectivity $\left(D^{*}\right)$ for Several Detectors

5 Detector Output Voltage Curve on Semi-Log Scale 16

6 Environmental Zones Imposed by the Turbine Engine on the Lens and Light Pipe Optical Systems

7 Lens Sensor Head Installed on T F-41 Type Engine

$8 \quad$ Lens Type Sensor Head

$9 \quad$ Aperture Type Sensor Head $\quad 21$

10 Aperture Sensor Head Installed on T F-41 Type Engine 22

11 Ray Diagram for a Coated Fiber $\quad 22$

12 TBTMS Readout and Control Unit $\quad 26$

13 TBTMS Readout and Control Functional Block Diagram , 27

14 Voltage Detection and Analysis Circuit Outputs 29.

15 Platform for Hybrid Circuits - Two are Employed 31

16 Hybrid Circuit Package. Two are Used in Each Signal Processor. 32

17 Frequency Response of Hybrid Filter $\quad 33$

18 Circuit Boards Used in TBTMS

19 Diagram of End-to-End Calibration Test $\quad 35$

$20 \quad$ TBTMS for Rocketdyne $\mathrm{LO}_{2}$ Turbopump $\quad 39$

21 TBTMS for Rocketdyne $\mathrm{LO}_{2}$ Turbopump 41 


\section{$\therefore$ TABLES}

Table

Page

I Data for Silicon Detectors $\quad 12$

II Error Due to Incorrect Emittance $\quad$ \& $\quad 12$

III Hybrid Linearizer Tests $\quad$. 32

IV TBTMS Instrument Calibration - Sensor Head Number 0-1 46

V TBTMS Instrument Calibration - Sensor Head Number 0-2 46

VI TBTMS Instrument Calibration - Sensor Head Number 100-1 47

VII TBTMS Instrument Calibration - Sensor Head Number 100-2 47 


\section{1}

\section{INTRODUCTION}

This report describes the results of a program that built a complete turbine blade temperature measurement system and tailored the optical heads to a $\mathrm{LO}_{\mathrm{X}}$ turbopump. The emphasis in this program was placed on tailoring proper sensor heads for the North American Rockwell turbopump which was specified by NASA representatives. Emphasis was placed on system performance with the goal of obtaining significantly useful data when the installation was completed by NASA. The majority of the program work entailed the tailoring of the sensor heads and the construction of the heads, cables and signal processor. Optical and system tests, reported in this text, were performed on completion of the construction phase.

While this system is specifically tailored for use on a particular pump, its use is not restricted to that application. The hardware delivered as part of this program can be used in some other situations if the geometry and dimensions are compatible. Some of the possible uses of this equipment are described in the remainder of this section.

\subsection{IMPORTANCE OF TURBINE BLADE TEMPERATURE MEASUREMENT}

increased gas turbine inlet temperatures combined with higher pressure ratios offer the greatest potential for improvements in the performance of advanced engines. Presently, experimental engines operating well above $2000^{\circ} \mathrm{F}$ are demonstrating that tremendous performance improvements are possible. At these very high inlet temperatures the key parameter required (turbine inlet gas temperature) cannot be measured directly with the present state-of-the-art sensors. Sensing and controlling this parameter is probably the most vital single item necessary to improve reliability and maintainability of modern aircraft. Performance of the engine is basically limited by the * need to operate hot metal parts at a temperature that allows long reliable life. Stress creep life is a strong exponential function of temperature. A few minutes of operation at overtemperature conditions can result in dramatic reductions in engine life and potentially catastrophic failure of the turbine. Advanced engines have turbine blades analogous to extremely high response heat exchangers operating with one fluid above the melting temperature of the metal. Turbine blade wall temperatures are a delicate balance between the extremely high heat flux input resulting from the high velocities, pressures and temperature downstream of the nozzle vanes and the cooling air flow within the blades. Only a minimum amount of cooling air is used, since engine 
$\mathrm{s}$ dramatically as cooling flow (compressor bleed) is increased. sscac unosumsunons and experience with present engines strongly indicate that reliability and maintainability factors can be significantly improved by the development of a reliable radiation pyrometer system specifically designed to interface with modern aircraft gas turbine engines.

Measurement of turbine blade temperature not only provides this vital metal temperature but is considered by many expert engineers a more accurate indication of inlet gas temperature than the standard exhaust gas thermocouple harness. Solar has recently completed a "Research Analysis of Advanced Sensors for Turbine Inlet Gas Temperature" (Ref. 1) for the Naval Air Systems Command. Its basic conclusion was that three concepts have the potential to be considered for TIGT (Turbine Inlet Gas Temperature) sensors; beta ray probe, ultrasonic air gap and immersed optical target. Of the three systems selected as potential TIGT sensors, none of them is sufficiently well advanced or miniaturized to be considered as possible sensors for the present production engines. Analysis of other alternate approaches was made in great detail. All immersion concepts were materials limited above $2000^{\circ} \mathrm{F}$. Fluidics, in addition basic materials problems, had severe contamination sensitivity since exhaust gas must pass directly through small diameter passages in the oscillators. Accuracy of fluidic elements at high temperature gas conditions was also found to be greatly dependent on incorporation of bulky radiation shielding which itself was life limited above $2000^{\circ} \mathrm{F}$. More detail analysis can be obtained on these alternate approaches together with detailed analysis of eight other methods in Reference 1. Throughout the course of that NASC program, it became relatively clear that many turbine engineers are convinced that the first order of priority should be given to a turbine blade temperature sensor rather than the longer range and much more difficult problem of a TIGT sensor. Additionally, many believe that the first stage blade temperature is a more accurate parameter from which TIGT can be deduced than the outputs of several thermocouples in the engine exhaust. Justification for this line of reasoning is based upon problems observed with present thermocouple harnesses:

- Even in the exhaust, large point-to-point variations in the gas temperature are observed. Since the thermocouple measures only a point temperature, many probes are necessary to give even reasonably accurate results.

- Thermocouple temperature as a result of drift, radiation losses, recovery factors, and conduction errors is not equal to gas temperature but only proportional.

- Response of thermocouples is poor since a type that can have reasonably long life must be relatively massive. 
- Turbine performance must be assumed to be constant and known in order to factor exhaust or downstream temperature into the TIGT parameter.

When these shortcomings are considered, the computed TIGT parameter must have an adequate safety margin applied to the answer. Since advanced engine TIGT studies are difficult if not impossible to make, even with laboratory equipment, no firm number can be quoted for the safety margin. Values ranging from 50 to $70^{\circ} \mathrm{F}$, however, are estimated. It is reasonable to assume that if the blade temperature is known within $\pm 20^{\circ} \mathrm{F}$, TIGT can be estimated with an accuracy much better than $\pm 50^{\circ} \mathrm{F}$. This estimate will have a higher degree of reliability and a faster characteristic response than that achieved with an exhaust thermocouple harness.

\subsection{PERFORMANCE DIAGNOSTIC USES OF TURBINE BLADE TEMPERATURE}

\subsubsection{Intelligence Available From a Radiation Pyrometer Sensor}

Radiant power proportional to the blade temperature is collected from a preselected target area by a sensor head. From the immediate area of the interface of the sensor with the engine, the signal is transmitted by flexible fiber optics to a relatively cool location remote from the turbine case. The radiant power is then converted by a silicon photovoltaic diode to an electrical signal for further processing. It has been determined by system analysis that the three most important temperature intelligence parameters that should be measured are:

-Average integrated temperature of all blades on a rotor.

-Average of the maximum peak temperatures of all the blades on a rotor.

- Maximum peak temperature of the single hottest blade on a rotor.

For flexibility and convenience this data can be used in three different outputs, a digital display in degrees $\mathrm{F}$, a high response linearized DC output voltage scaled to $1 \mathrm{mV}=1^{\circ} \mathrm{F}$, or a high response nonlinear signal.

\subsubsection{Control Parameters}

Turbine blade temperature control in engines is one of the most critical factors in the design of an engine. Advanced technology engines operate with turbine inlet gas temperatures well above the safe limits of the metal to achieve low specific fuel consumption and high specific power per unit weight and volume. These engines depend upon diverting compressor discharge air to cool the blades and other hot engine parts. The 
work added to the compressor air used for blade cooling is largely lost. 'Thus it becomes important to operate the blades as near the maximum temperature allowed by the material life factors. At these high inlet temperatures, $1900^{\circ} \mathrm{F}$ and above, and with air cooled blades operating at high pressure ratios the temperature response of each blade becomes a critical balance between very high convective heat inputs and internal convective cooling. Under many operating flight conditions the thermal time constant of advanced technology engine blades is less than one second. Thus conventional methods of preventing overtemperature, previously found to be adequate, are now becoming increasingly less satisfactory. If indirect parameters are used to compute factors to control blade temperatures, a relatively large margin must be provided for hardware safety. Since a few degrees change in gas temperature can siginificantly effect performance and life, the gains obtained by optimizing the blade temperature control by direct measurement can be potentially decisive for certain aircraft mission requirements. For variable geometry engines, the above factors become less accurate.

\subsubsection{Reliability and Maintainability Parameters}

From the information contained in the sensor output signal, the basic health of a number of critical engine components or systems can be directly appraised or indirectly deduced. By comparing the average temperature of all the blades on a rotor with controlled condition test stand results, the general condition of a field engine can be established. An envelope of pressure, torque, speed and blade temperature could be established that related limits of performance of an acceptable engine. If blade temperature were used for this criteria, a more accurate general engine status. would be possible since critical blade cooling performance would be directly factored into the engine diagnostic parameters. Cooling system status to the entire rotor or any one blade could be readily diagnosed by means of a blade sensor system. Contamination, fouling, erosion, leakage, blockage, quality control, or other possible cooling system failures would show up differences between average, average peak and maximum peak blade temperature. For example, if oil or sand and dust were ingested in sufficient quantities into the cooling air system to cause blockage or a general buildup of insulating coatings within the blade passages, the difference between average blade and average peak blade temperature would increase. Differences between these two parameters of as little as $10^{\circ} \mathrm{F}$ are expected to be readily detectable and thus slight changes in the cooling air system will be readily detectable. If a single blade were to start to overheat due to cooling blockage or a puncture in a cooling passage (from ingested or upstream objects), the difference between the maximum peak and average peak temperature signals could diagnose these at their earliest stages.

By making a continuous recording of blade temperature data throughout the operating envelope of the engine, an excellent diagnostic analysis of the fuel control systems performance could be established. Starts, accelerations, rated power, 
military power and power level transient operating can be analyzed with respect to the turbine rotor. Comparisons between initial test stand calibrations and field or operations diagnostic operations will enable end-to-end evaluation of the control system performance.

If a continuous record is maintained by the incorporation of a simple creep life computer, basic life data will be available. A small "black box" that accepts speed and blade temperature inputs can yield data on the creep life remaining on a particular turbine rotor. Thus effects of surge, hot starts, suspected overtemperature, control system malfunctions, cooling abnormalities, and emergency military power demands can be directly accounted for between major overhauls of the engine. The effects of these overtemperature operating conditions on the creep life and thermal fatigue life can be factored into the maintenance plan before actual failures occur in operation. Continuous monitoring and recording of blade temperatures could thus become a vital part of engine diagnostic and preventive maintenance plans, resulting in greater reliability with greater-mean-time-between-overhauls. By incorporation of this relatively inexpensive sensor system, overall maintenance costs would be expected to be significantly improved at the same time aircraft reliability and availability are increased.

\subsubsection{Engine Test Analysis and Development}

Test cell operation, analysis, control and development can be greatly improved by exact knowledge of the turbine blade temperatures. Effects of changes of any of the engines' operating systems or parameters upon the most critical of all parameters can be immediately and efficiently ascertained. Control system modification or tolerance studies, altitude, inlet distortions, combustor modifications, system damage, salt spray, sand and dust, etc., are just a few test conditions in which blade temperature data would be useful if not vital. Blade cooling, coating or other design modifications, of course, require knowledge of the blade temperature. Present blade designs do not lend themselves to installation of thermocouples due to the very thin walls. If thermocouples are installed, they always have an undesirable heat balance effect that modifies the temperature they were "intended to measure. Their life is short and installation cost is high. Efficient temperature mapping of air cooled blades is essentially impossible and significant; compromises are usually made (together with "guesstimates" based upon inadequate data). The development of engine compatible turbine blade pyrometry makes efficient engine analysis possible at relatively low costs. An important side benefit is the ability of a TBTMS system to save engines from destruction if anomalies occur in the control, combustor or cooling system. 


\subsection{CONCLUSIONS}

A TBTMS has been specifically tailored to the North American Rockwell $\mathrm{LO}_{\mathrm{x}}$ turbopump. The system includes a three-mode, two-input signal processor, interconnecting cable, and four sensor heads. Two of the heads are aperture type, while the other two are lens type. This system should provide significant blade temperature data in the range of $1400-2200^{\circ} \mathrm{F}$. Long lifetime components have been used throughout to assure proper service under turbine conditions. 


\section{. \\ PRINCIPLES OF OPERATION}

\subsection{TURBINE BLADE TEMPERATURE MEASUREMENT SYSTEM}

The temperature measurement system views the rotating turbine blades and by measuring the emitted, electromagnetic radiation produces a signal directly proportional to the temperature of the blades. The system is shown schematically in Figure 1. The sensor head containing the optical system is attached to the outer case of the turbine with a clear optical path from the objective aperture to the turbine blades. The area on the blade from which radiation is accepted is called the target area. Energy is radiated from a solid target as a function of its temperature and the emittance of its surface. The sensor head holds the optics in position and provides a stream of purge air to maintain the optical window free from soot, dirt or other contaminants that would block transmission. The optical system generally consists of a lens or light pipe and aperture to gather the radiation from the blades and define the target area and a fiber optic bundle to transmit the radiation to the detector.

Solid state detectors produce an electrical current proportional to the radiant power incident upon their surface within a spectral band characteristic of the detector. Silicon detectors have been shown to be effective for turbine applications when operated in the photovoltaic mode. Silicon detectors are responsive to radiation between approximately 0.4 and 1.1 microns. The radiation intensity over this spectral band is exponentially proportional to temperature, thus causing the detector to produce a current that charges logarithmically with the target temperature.

The logarithmic cirrent provided to the signal processor varies as a function of time as the blades pass through the optical path of the sensor. The signal processor operates on this signal to extract temperature information of interest, linearizes the signal as a function of temperature and provides linear digital and analog output signals for control, data acquisition, overtemperature protection and direct readout. Information available in the detector output signal includes:

- Average temperature of the blades

- Average leading edge temperature (assuming the leading edge is the hottest part of each blade) 


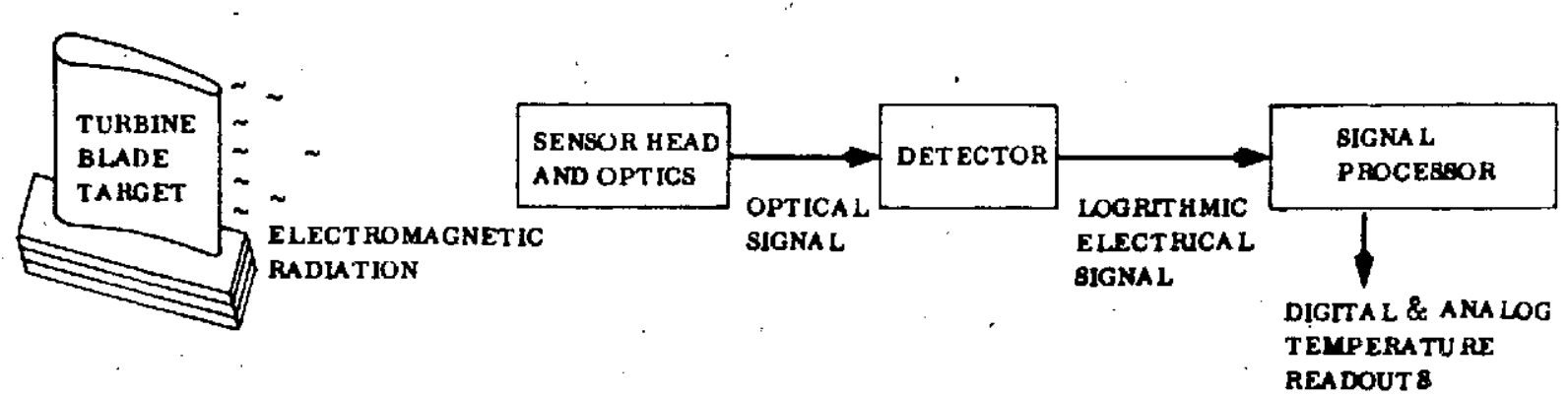

FIGURE 1. TURBINE BLADE TEMPERATURE MEASUREMENT SYSTEM

- Maximum blade temperature (hottest blade)

- Individual blade thermal gradients

- Turbine wheel speed (proportional to blade passing frequency)

- Creep life expended (or remaining) calculated from an integrated temperature-time-stress (speed) equation

- Thermal fatigue from start up or over power transients

The portion of the available information extracted from the detector signal by the signal processor is dependent on the intended application. Three parameters have been selected as the most meaningful for turbine control:

- The maximum temperature measured during each revolution (Max. Peak)

- The average of the maximum individual blade temperatures (Avg. Peak)

- The average measured temperature (Avg.)

The current design incorporates a digital display of those signals and provides a linear analog signal output. 


\subsection{PHYSICAL LAWS GOVERNING RADIATION PYROMETRY}

All matter emits radiant energy to its surroundings as a function of temperature. Solids radiate at all wavelengths; the amount of power radiated at each wavelength is a function of temperature and the surface conditions of the emitting body. A perfect emitter, called a blackbody, absorbs all radiation incident upon its surface. All real surfaces radiate a lesser amount of energy at all wavelengths. The ratio between blackbody radiation, for which mathematical treatment is available, and the radiation from a real surface is called the emittance.

Radiation from a blackbody, $\mathrm{N}_{\mathrm{b} \lambda}$, is given by the Planck function.

$$
\mathrm{N}_{\mathrm{b} \lambda}=\mathrm{C}_{1} \lambda^{-5}\left(\exp \left(\mathrm{C}_{2} / \lambda \mathrm{T}\right)-1\right)^{-1}
$$

where

$$
\begin{aligned}
\mathrm{N}_{\mathrm{b} \lambda} & =\text { radiance at wavelength } \lambda\left(\text { watts } / \mathrm{cm}^{2}\right) \\
\mathrm{T} & =\text { temperature }\left({ }^{\circ} \mathrm{K}\right) \\
\lambda & =\text { wavelength }(\mathrm{cm}) \\
\mathrm{C}_{1} & \left.=\text { constant }=3.7413 \times 10^{-12} \text { (watt } \mathrm{cm}^{2}\right) \\
\mathrm{C}_{2} & =\text { constant }=1.4388(\mathrm{~cm} \text { degree } \mathrm{K})
\end{aligned}
$$

Radiation from a real surface $\mathrm{N}_{\lambda}$ is found by multiplying $\mathrm{N}_{\mathrm{b} \lambda}$ by the emissivity, $\epsilon_{\lambda}$, which is a function of wavelength and is less than one. A plot of the dependence of radiant power on wavelength for a blackbody $\left(\epsilon_{\lambda}=1\right.$ for all $\left.\lambda\right)$ is shown in Figure 2 for several temperatures. The radiant power emitted at all wavelengths increases with increasing temperature. There is a wavelength at which the radiant power is a maximum and this maximum occurs at shorter wavelengths as the temperature increases, according to Wien's displacement law:

$$
\lambda_{\max } \mathrm{T}=2897 \text { micron degree } \mathrm{K}
$$

where $\begin{aligned} \lambda_{\max } & =\text { Wavelength for maximum radiance (microns) } \\ T & =\text { Temperature }\left({ }^{\circ} \mathrm{K}\right)\end{aligned}$

The total amount of energy radiated at all wavelengths increases as the fourth power of temperature according to the Stefan-Bolzmann law:

$$
N_{\text {total }}=\epsilon_{0-\infty} g T^{4}
$$




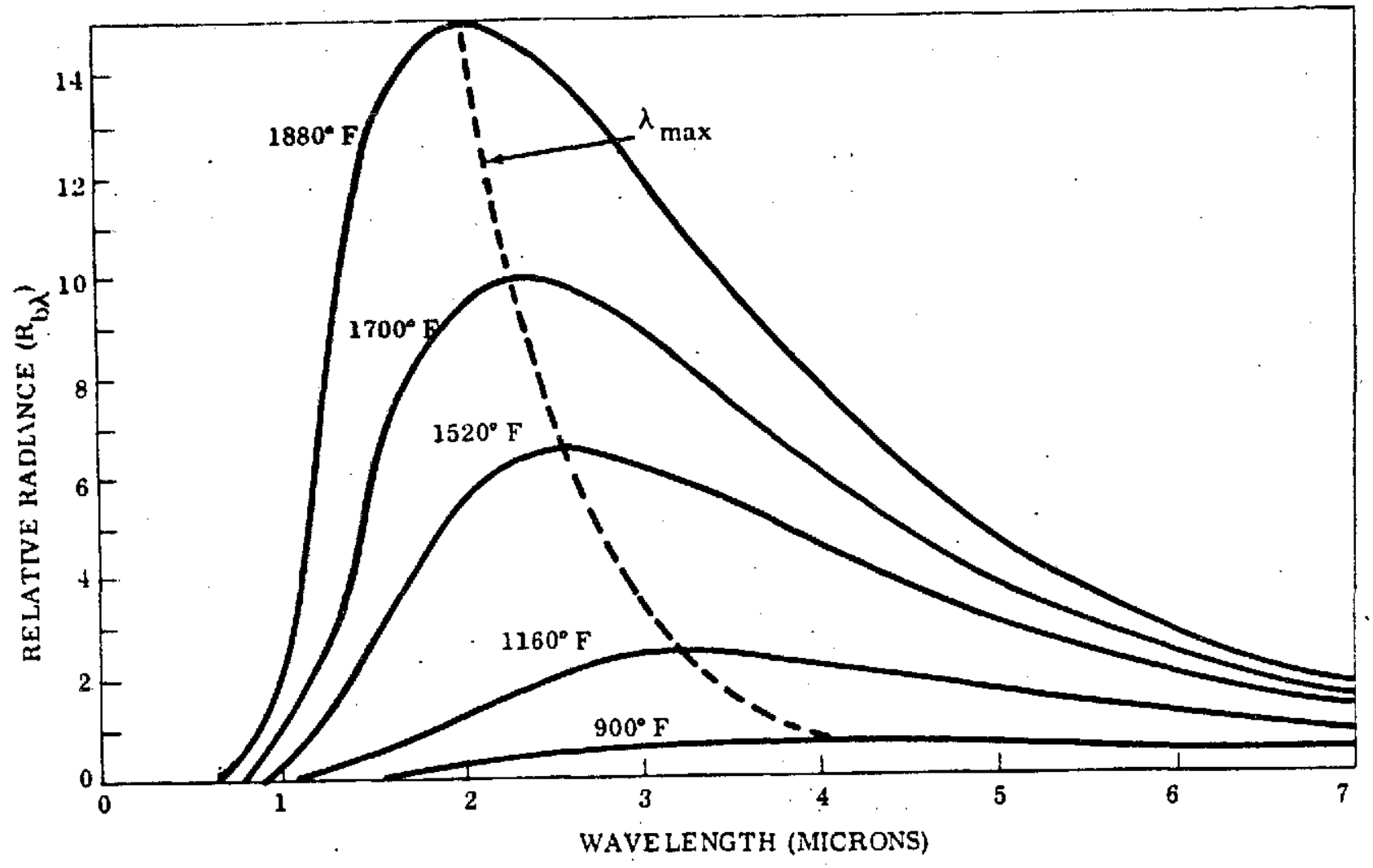

FIGURE 2. BLACKBODY RADIANCE FOR SEVERAL TEMPERATURES

where

$$
\begin{aligned}
\sigma= & \text { Stefan-Bolzmann constant }=5.699 \times 10^{-12} \mathrm{watts} / \mathrm{cm}^{2} \\
& \text { degree } \mathrm{K} \\
\epsilon_{0-\infty}= & \text { Total emittance }
\end{aligned}
$$

The radiation emitted by a solid body is approximately given by Wien's equation as a function of wavelength and temperature.

$$
N_{b \lambda}=c_{1}^{\cdot} \lambda^{-5}\left(\exp -c_{2} / \lambda T\right)
$$

Wlen's equation Is within 1 percent of the Planck function for all conditions were

$$
\lambda T \leq 3000 \text { micron degrees Kelvin }
$$

thus for wavelengths near 1 micron Wien's equation holds for temperatures up to $3000^{\circ} \mathrm{K}\left(2727^{\circ} \mathrm{C}, 4946^{\circ} \mathrm{F}\right)$.

The properties of radiation detectors may be more easily analyzed by an exponential equation for the radiance of the type: 


$$
\mathrm{N}_{\lambda}=\epsilon_{\lambda} \mathrm{KT}^{\mathrm{n}}
$$

where $\mathrm{K}$ is a constant.

By differentiating and substituting with Wien's equation, the exponent, $n$, is found to be a function of wavelength and temperature, and is given by:

$$
\mathrm{n}=\mathrm{C}_{2} / \lambda \mathrm{T}
$$

Radiation detectors produce a signal, $S$, proportional to the radiant energy incident upon their surface within their spectral range. The relationship between output signal and target temperature is exhibited by equation 6 . High sensitivity (large change in signal per unit change in temperature) corresponds to large changes in radiance per unit change in temperature and thus to a high value of $n$. Equation 7 shows $n$ to be a function of wavelength and temperature. The wavelength used to calculate $\mathrm{n}$ is fixed by the spectral range of the detector. A lower wavelength corresponds to a higher value of $\mathbf{n}$ and in turn to a signal more responsive to target temperature. The detector output $S$ is given by

$$
s=R_{\lambda} \epsilon_{\lambda} F N_{b \lambda}
$$

where

$$
\begin{aligned}
& \mathrm{R}_{\lambda}=\text { Detector responsivity (amps/watt) } \\
& F_{.}=\text {Optical transfer factor (area }{ }^{-1} \text { ) }
\end{aligned}
$$

Differentiating with respect to temperature derives the following equation for the sensitivity as a fractional change in signal per unit change in temperature:

$$
\frac{\mathrm{dS} / \mathrm{dT}}{\mathrm{S}}=n \mathrm{~T}^{-1} \frac{\mathrm{C}_{2}}{\lambda \mathrm{T}^{2}}
$$

Sensitivity is directly proportional to the value of $n$. For detectors that are responsive to a narrow band of wavelengths, an effective wavelength may be calculated to allow the use of the formulas derived for monochromatic radiation (Ref. 2). Table I shows the effective wavelength for silicon (Ref. 3), the temperature exponent, $n$, and the calculated sensitivity for silicon detectors. 
TABLE I

DATA FOR SILICON DETECTORS

\begin{tabular}{|c|c|c|c|c|}
\hline \multicolumn{2}{|c|}{ Temperature } & $\begin{array}{c}\text { Effective Wavelength } \\
(\mu)\end{array}$ & $\begin{array}{c}\text { Temperature Exponent } \\
\left(\mathrm{T} \text { in }{ }^{\circ} \mathrm{K}\right)\end{array}$ & $\begin{array}{c}\text { Sensitivity } \\
\left(\% /{ }^{\circ} \mathrm{F}\right)\end{array}$ \\
\hline$\left.{ }^{\circ} \mathrm{F}\right)$ & $\left({ }^{\circ} \mathrm{C}\right)$ & 0.98 & 19.0 & 2.5 \\
932 & 500 & 0.91 & 12.4 & 1.0 \\
2732 & 1000 & 0.86 & 9.6 & 0.5 \\
\hline
\end{tabular}

Detectors with high values of $\mathrm{n}$ are also insensitive to changes or uncertainties in target emittance or optical transfer factor, $F$. The optical transfer factor is a proportionality constant relating the radiance (watts per unit area) leaving the target to. power (watts) arriving at the detector. The transfer factor takes in account target areas, lens areas, loss-in the optical system and view distance. A pyrometer is calibrated at known conditions of emittance $\epsilon_{c}$ and transfer factor $F_{c}$. If in use the emittance $\epsilon$ or the transfer factor $F$ are not equal to the values at calibration, an error in indicated temperature $T_{i}$ will result. The magnitude of the error is shown by differentiating equation 8 with respect to $\epsilon$ and $F$. The fractional error between indicated and true temperature is given by:

$$
\frac{T-T_{i}}{T_{i}}=\left(\frac{\epsilon_{c}}{\epsilon}\right)^{1 / n}\left(\frac{F_{c}}{F_{t}}\right)^{1 / n}-1
$$

If $\epsilon=\epsilon_{c}$ and $F_{t}=F_{c}, T_{i}=T$ and there is no error. The higher the value of $n$ the lower the resulting error from a given change in emittance or optical conditions. Table II shows the temperature error for three values of $n$. For a total

\section{- TABLE II}

ERROR DUE TO INCORRECT EMITTANCE

\begin{tabular}{|c|c|c|c|c|}
\hline \multirow{2}{*}{$\epsilon_{\mathrm{c}}^{-} / \epsilon$} & \multicolumn{2}{|c|}{ Temperature Error (\%) } & \multirow{2}{*}{ Remarks } \\
\cline { 2 - 5 } & $\mathrm{n}=4$ & $\mathrm{n}=10$ & $\mathrm{n}=20$ & Remon \\
\hline 2.0 & 18 & 7 & 3.5 & $\mathrm{~T}>\mathrm{T}_{\mathrm{i}}$ \\
1.0 & 0 & 0 & 0 & $\mathrm{~T}=\mathrm{T}_{\mathrm{i}}$ \\
0.5 & 16 & 7 & 3.5 & $\mathrm{~T}<\mathrm{T}_{\mathfrak{i}}$ \\
\hline
\end{tabular}


radiation pyrometer $\mathrm{n}$ is equal to 4. Values of $\mathrm{n}$ from 10 to 20 are typical of silicon detectors. A 10 percent error in emittance $\left(\epsilon_{\mathrm{c}} / \epsilon=0.9\right)$ produces only a 0.6 to 1.1 percent error in indicated temperature.

Another possible source of error is interaction of the radiated signal with the hot turbine gas flowing between the turbine blade and the optical system. Especially critical are the absorption and emission bands characteristic of the constituent species in the turbine gas. Principal components are $\mathrm{H}_{2} \mathrm{O}, \mathrm{CO}, \mathrm{CO}_{2}$. and unburned fuel. Figure 3 shows the radiance from an $1832^{\circ} \mathrm{F}$ blackbody target emitted radiation from the gas, and the spectral range of silicon detectors as a function of wavelength. Silicon has a peak responsivity at approximately 0.85 microns and significant acceptance of radiation from approximately 0.4 to 1.1 microns. This spectral region avoids all of the absorption and emission from the turbine gases.

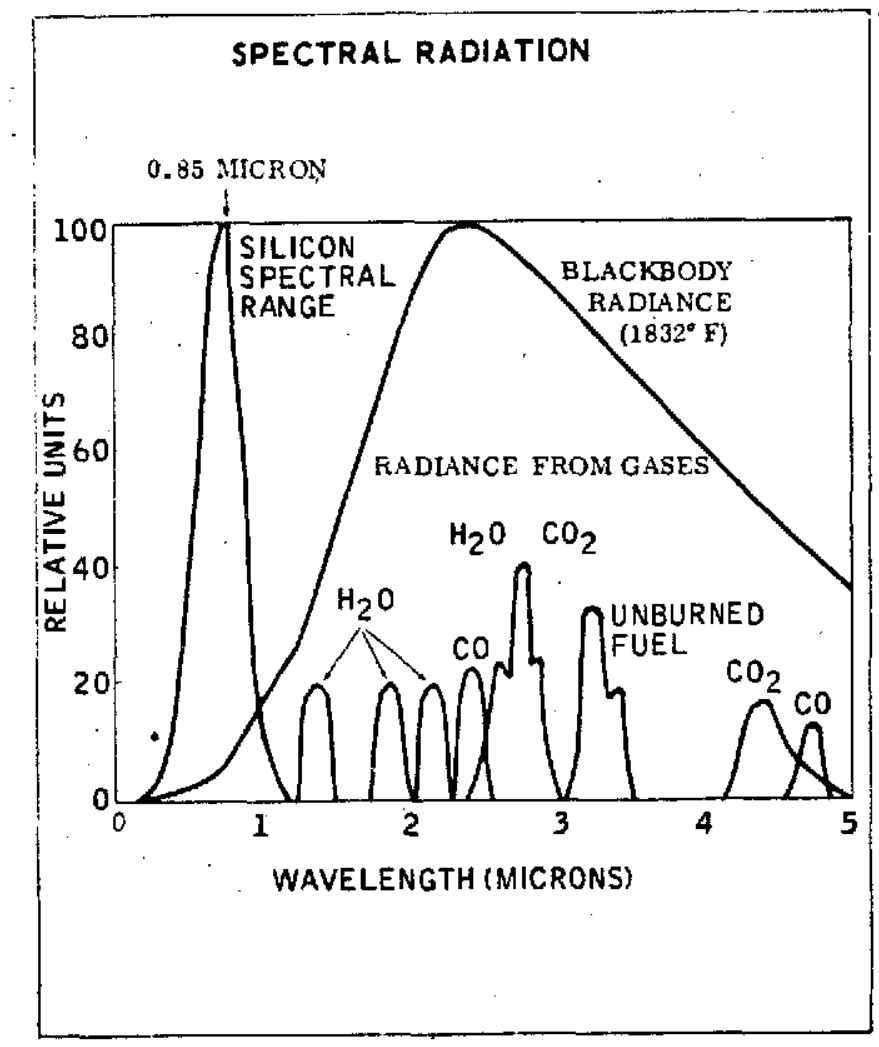

FIGURE 3. SPECTRAL RESPONSE OF SILICON AND RADIANCE FROM BLACKBODY AND TURBINE GASES 


\subsection{RADLATION DETECTOR}

The key component in a radiation pyrometer is the detector that transduces optical radiation into an electrical signal. The parameters, properties and characteristics of the detector to a large extent define the performance of the entire temperature measurement system. A brightness pyrometer measures the intensity of the radiation incident on the detector. Each type of detector is sensitive to radiation in a different range of wavelengths. Several phenomenological parameters are in general use to describe the performance of radiation detectors (Ref. 4).

Most detectors are used in a range where output is proportional to input. The ratio of output to input is called the responsivity, $R_{\lambda^{*}}$. The units of responsivity are volts per watt. In the case of photovoltaic sensors operated in the short circuited mode, responsivity given in amps per watt is more useful. The term sensitivity is also often used in place of responsivity, but its general use for a number of related concepts make it somewhat ambiguous. The responsivity of a detector relates output to input but does not give any information as to how small a signal can be measured.

The minimum measurable signal is controlled by the level of the electrical noise in the output signal. If the rms voltage of the noise is divided by the responsivity (in volts per watt) the noise equivalent power (N.E. P.) of the detector results. The noise equivalent power is numerically equal to the radiant input power needed to produce a greater output signal from a given radiant input than a less responsive detector. A detector with a smaller noise equivalent power will have a greater detecting ability. The reciprocal of the noise equivalent power, called the detectivity, is thus a direct measure of the detecting ability of the detector. Noise equivalent power and detectivity a re complex and ill-defined functions of a number of variables such as detector area, frequency, temperature, gain and power level. Each parameter must be specified in a standard condition to allow comparison of one detector with another. Detectivity is usually specified "In the reference condition $E^{\prime \prime}$ and is written as $D^{*}$. Detectivity $\left(D^{*}\right)$ is shown in Figure 4 as a function of wavelength, $\lambda$, for several detectors. The spectral response characteristics of each type detector are readily apparent. Silicon is seen to have a very high detectivity and a narrow spectral bandwidth.

Silicon radiation detectors have been used almost exclusively during the development of the TBTMS. Silicon detectors from several manufacturers have been tested and evaluated. No one detector manufacturer has proven to have an optimum detector for this application. Detectors must be rugged and small, and have low capacitance for the highest frequency response. Also, the detectors must display a reasonably linear change in output as a function of temperature. This is discussed in more detail in Section 3. 


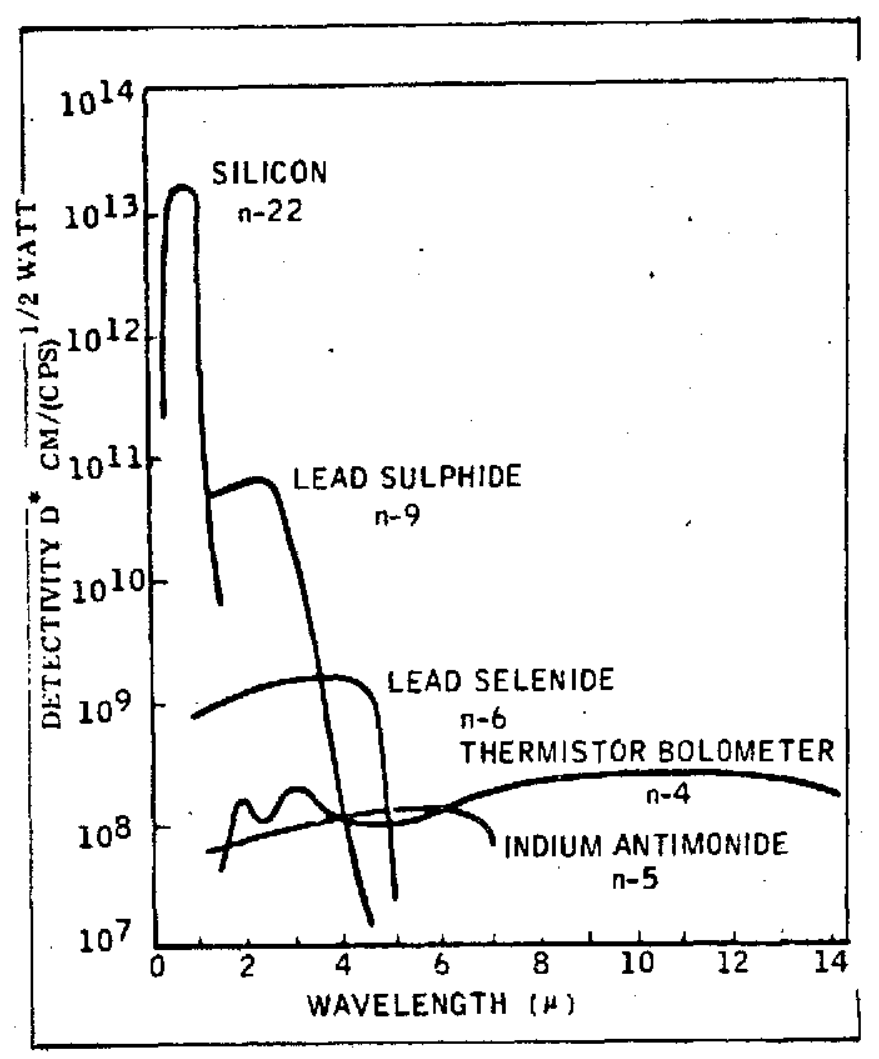

FIGURE 4. DETECTIVITY (D*) FOR SEVERAL DETECTORS (Ref. 4)

Among silicon detectors there are three main types, surface barriers, diffused junction and lithium drifted. The active junction is usually formed by depositing a thin film of gold on the surface of $n$ silicon for surface barrier type detectors. A diffused diode is produced by diffusion of an impurity into $n$ or $p$ type silicon to produce an $n-p$ junction. The active area of the third type is an intrinsic region of silicon produced by the diffusion of lithium in $n$ type silicon. The three types of detectors have different responsivity to radiation over the wavelength of interest. Thus, one type must be chosen and used consistently once a calibration curve has been developed and incorporated into the electronic signal processsor. Because of a stronger "blue" response and a tendency toward instabilities the surface barrier type detectors have not been used. Lithium drifted detectors must be cooled at all times to avoid further drifting. A practical T BTMS cannot use such a detector. The diffused junction detectors have proved to be dependable and reliable in this application. Among the diffused junction detectors tested, the calibration curve (output current versus turbine blade temperature) remains within a few percent. Figure 5 shows a typical calibration curve.

The calibration is accomplished with a heated strip target, a sensor head, filter optic cable, a detector and an amplifier. The thermal radiation is transmitted from the temperature controlled target to the detector via the sensor head and converted to a current at the detector. The electrical current is run into an operational amplifier 


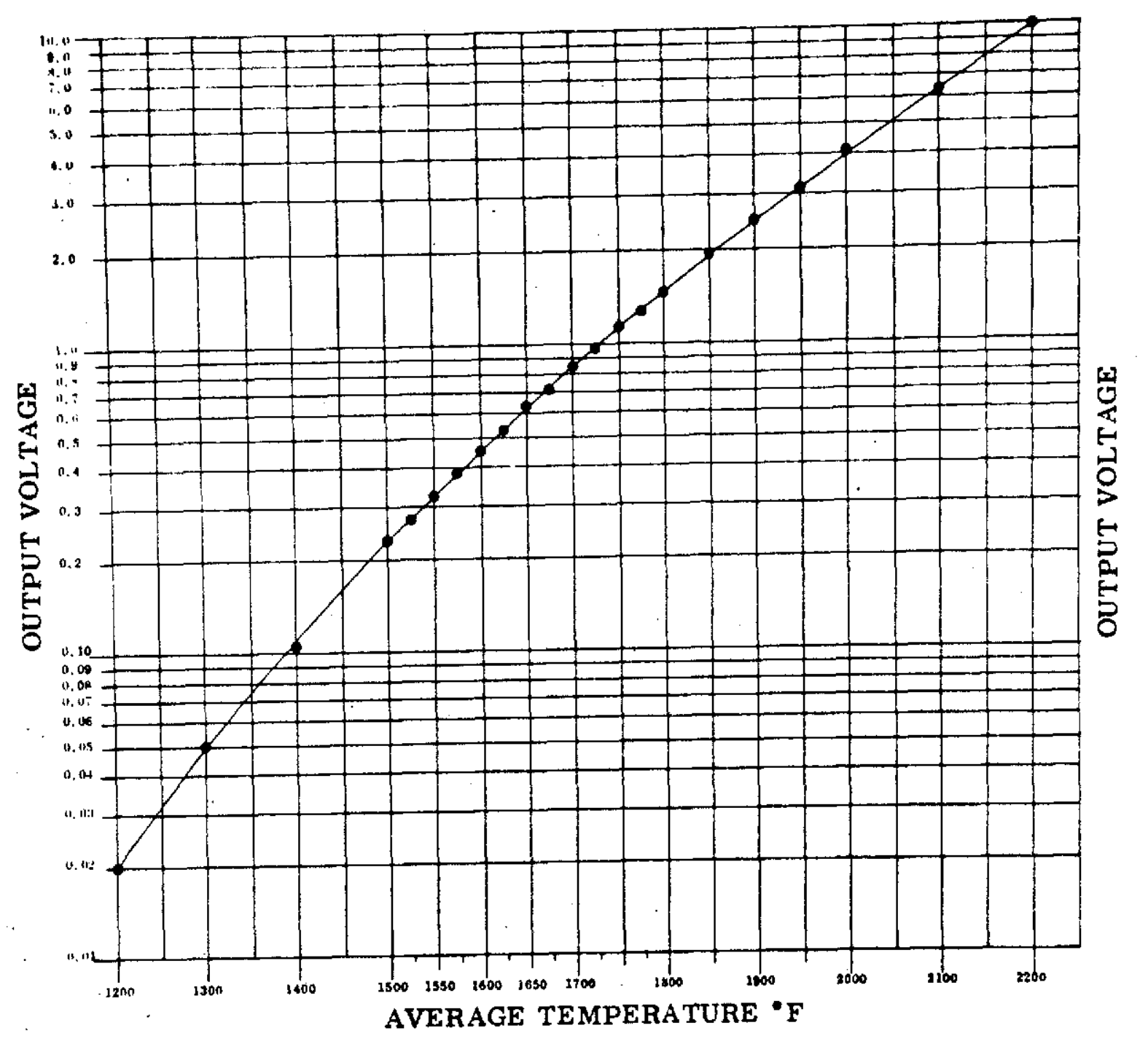

FIGURE 5. DETECTOR OUTPUT VOLTAGE CURVE ON SEMI-LOG SCALE

which produces a voltage output. Normal detector current levels range from $10^{-8}$ to $10^{-5}$ amperes. To eliminate losing the small signal in detector dark current, the detector is operated unbiased (photovoltaically). The operational amplifier configuration simulates a short circuit configuration for the detector which has been shown to result in the greatest signal stability over the operating temperature.

The main problem associated with the use of silicon detectors is drift in the output signal due to changing environmental temperatures. As the environmental temperature of the silicon detector is increased, its generated output current will rise independent of radiant power input. Most of the increase in current output results from a decrease in photon energy needed to break the valence bond within the junction. Thus the spectral response is enhanced at long wavelengths when the detector is warm. The current generated increases approximately linearly at a rate of 0.25 percent per 
degree $\mathrm{F}$ in the range from -50 to $125^{\circ} \mathrm{C}$. Solutions to this problem are discussed in Chapter 3.

In general the silicon detectors are small, rugged, require no external power supplies, and are sensitive to radiation in a narrow spectral region that is devoid of gas absorption or emission peaks. Operation to $250^{\circ} \mathrm{F}$ is practical and overtemperature of $300^{\circ} \mathrm{F}$ have been experienced with no appreciable degredation. Because.of severe signal compensation problems, operation at temperatures over $220^{\circ} \mathrm{F}$ is not recommended.

\subsection{OPTICAL SYSTEM}

The purpose of the optical system is to define the target area on the surface of the blades and to direct the radiant energy onto the detector. Remote placement of the detector due to its limited temperature capabilities makes the use of a light pipe or fiber optic bundle necessary. The sensor head holds the objective end of the optical system in the proper geometric relationship to the target and provides an interface between the optic and the engine. Purge air flowing through the sensor head maintains the cleanliness of the objective window.

There are two basic types of optical systems applicable to turbine blade temperature measurement systems. Figure 6 shows a schematic diagram of lens and light pipe optical systems with the principal environmental temperature zones imposed by the engine. A lens system, Figure $6 \mathrm{~A}$, uses an objective lens to focus the radiation onto a field aperture which defines the target size and shape. The radiation is then transmitted to the cooled detector by a solid light pipe, flexible fiber optic bundle or combination of the two types. Typical objective aperture diameter is 0.4 -inch with 0.1 to 0.25 inch target diameters. Figure $6 \mathrm{~B}$ shows a light pipe system where the radiation is accepted by the light pipe within a cone of half angle usually equal to 15 to 30 degrees, thus defining a target area on the blade surface. In comparison with the lens system, the objective aperture of a light pipe system is small, typically 0.060inch diameter, and the target area is large, 0.3 to 0.5 inch. The temperature imposed on each section of the optics is shown in Figure 6.

\subsection{LENS TYPE SENSOR}

The objective lens focuses radiation from the target onto the fiber optic bundle. Focal length, geometry, and the size of the field aperture opening define the target size. The radiant power incident on a detector through such a sensor head upon the silicon detector is

$$
\varphi=F \in N_{b \lambda}(T)
$$




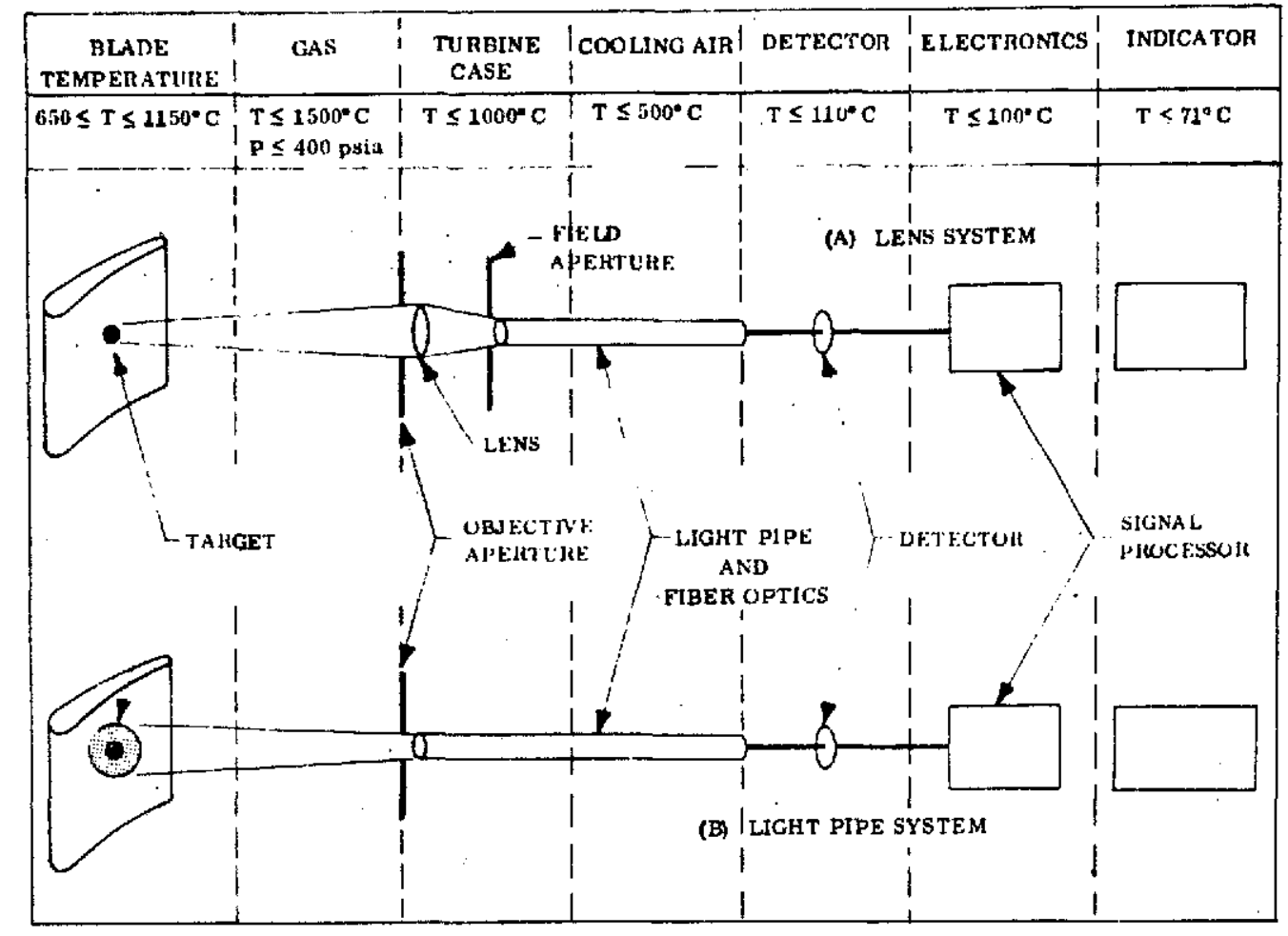

FIGURE 6. ENVIRONMENTAL ZONES IMPOSED BY THE TURBINE ENGINE ON THE LENS AND LIGHT PIPE OPTICAL SYSTEMS

where $F$ is an optical transfer function for both the lens and fiber optics, is the emissivity of the turbine blade and $\mathrm{N}_{\mathrm{b}}(\mathrm{T})$ is the power radiated from a blackbody at temperature, $\mathrm{T}$.

A high value for the transfer factor signifies a higher signal and thus a lower minimum temperature capability for the system. From an operational standpoint, however, small objective lens and target areas, as well as long target to lens distances, are preferred. The conflicting criteria must be compromised for each type of engine and application.

The objective lens may be made from fused quartz or sapphire. These materials combine the necesaary high temperature capabilities with high transmission in the near infrared. The lens diameter and focal length are, in general, made as small as possible. Diameters of $1 / 2$-inch are typical.

Figure 7 shows a lens system installed on a turbofan engine such as the TF-41. Installation is simple with two bolts holding the unit to the turbine case. Access is through a cover place on the fan duct housing. When not in use, the unit can be replaced with a plug to seal openings in the engine housings. If required, a streamlined sheetmetal fairing can be installed over the unit. A photograph of a lens sensor head currently installed on a turbine simulator for development tests is shown in Figure 8. 


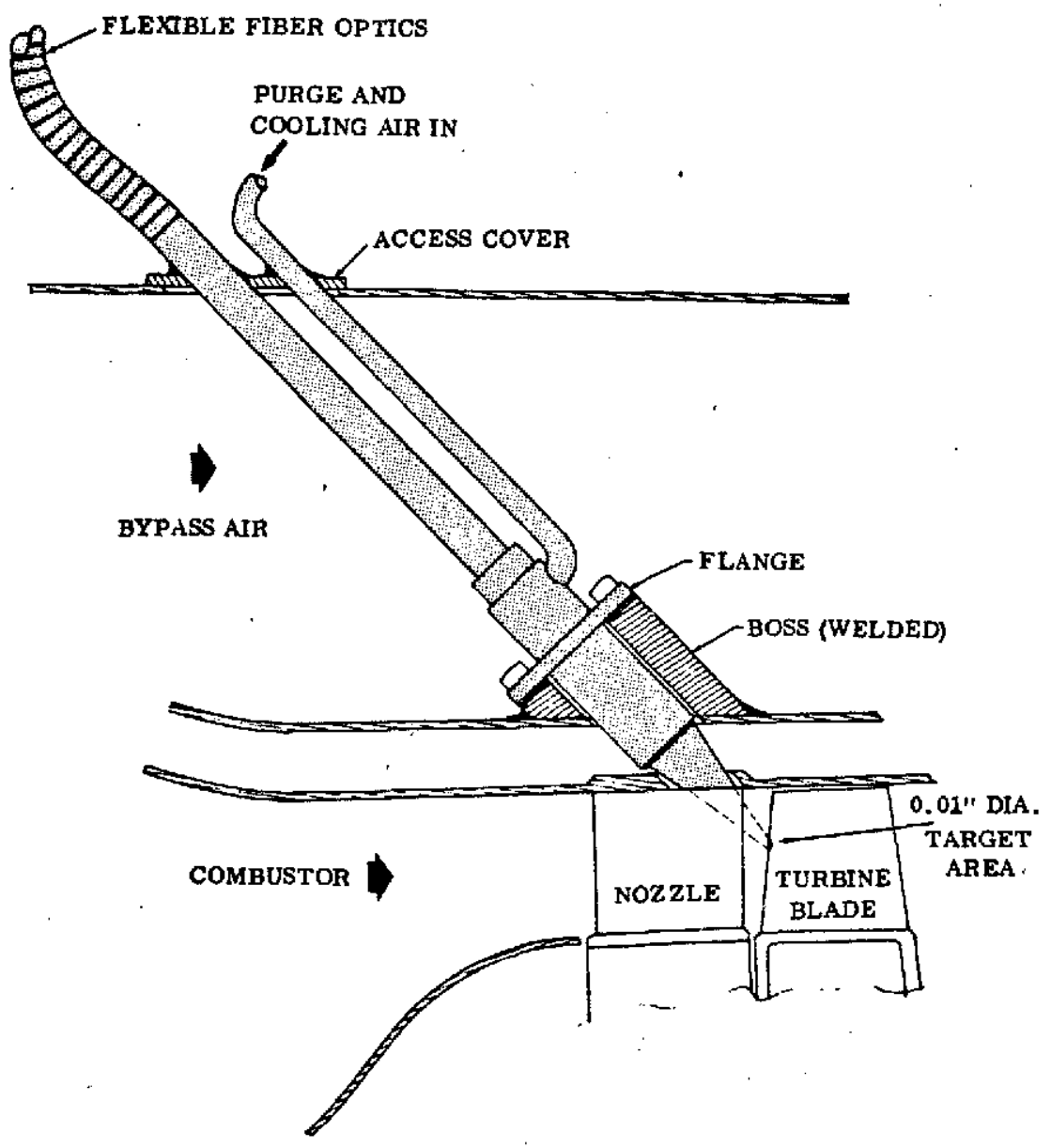

FIGURE 7. LENS SENSOR HEAD INSTALLED ON TF-41 TYPE ENGINE

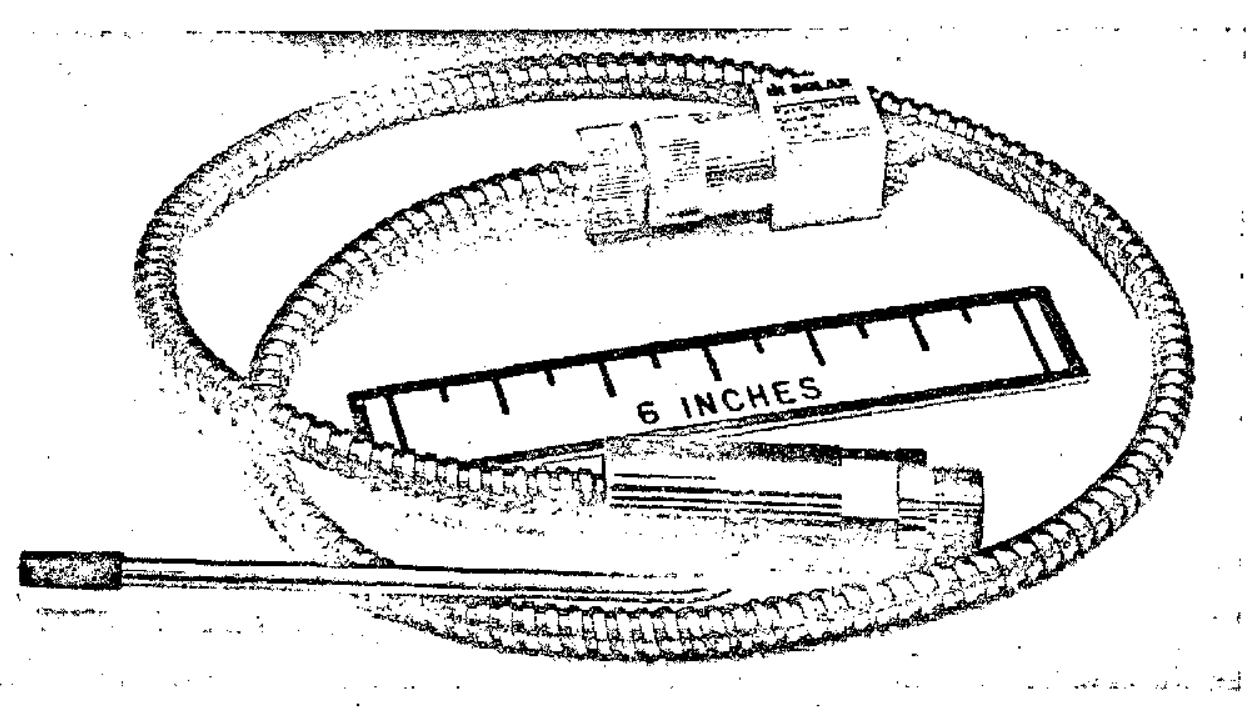

FIGURE 8. LENS TYPE SENSOR HEAD 


\subsection{APERTURE TYPE SENSOR HEAD}

The aperture sensor head accepts thermal radiation from a relatively large area of the turbine blade. The radiation energy passes through the aperture and is incident on a solid light pipe. This light pipe may be made from glass fiber optics or quartz in high temperature applications. Energy transmitted by the light pipe is transferred to a flexible fiber optic cable inside the sensor head. A silicon detector is placed at the end of the fiber optics. The target area is defined by the distance from the target to the aperture, the aperture size, and the distance from the aperture to the light pipe. In some cases the acceptance angle of the fiber optic light pipe affects the area of the target that is monitored. In a typical installation, the aperture is $0.040 \mathrm{inch}$ in diameter, between one and two inches from the target and $0.3 \mathrm{inch}$ from the light pipe. In this example an area $0.6 \mathrm{inch}$ is diameter on the target contributes to the observed signal. Purge air bled through this sensor head prevents the buildup of soot on the optical components and cools the aperture to prevent it from . radiating and thus influencing the signal. Figures 9 and 10 respectively, show an actual aperture type sensor and the functional aspects of a sensor of that type.

Although the aperture sensor head receives radiation from a large target area, it is preferred in many engine applications over the lens type sensor head which can accurately measure the temperature of a small spot (typically 0.150 inch in diameter). The tip of the aperture type sensor which penetrates the cooling jacket of an axial flow engine is only 0.250 inch in diameter. Also, the opening into the turbine area can be as small as 0.040 inch. The result of the small dimensions is a sensor that produces minimum pertrubation on engine operation. The lens type sensor may require a 1.0 inch opening in the engine cooling jacket and a 0.5 inch diameter opening into the turbine section.

\subsection{FIBER OPTICS}

Fiber optics technology is based on the phenomenon of total internal reflection. Each fiber is made up of a core glass with an index of refraction $\mathrm{N}_{1}$ coated with a second glass with an index of ref raction $\mathrm{N}_{2}$ where $\mathrm{N}_{1}>\mathrm{N}_{2}$. Each fiber accepts light for total internal reflection only within a cone of half angle $\theta^{\prime}$ defined by the equation:

$$
\text { Sine } \theta^{\prime}=\mathrm{NA}=\mathrm{N}_{1}^{2}-\mathrm{N}_{2}^{2}
$$

The numerical aperture NA is defined as the sine of the limiting half angle $\theta^{\prime}$. This is the maximum angle at which a ray incident on the fiber will be transmitted. The ray will exit from fiber at the same angle as it entered as is shown in Figure 11.

Absolute transmission by the fiber bundle is dependent on the transmission area of the core material, Fresnel reflection at the fiber ends, surface finish of the ends, and absorption and scattering within the fiber. Reflections at each end are 


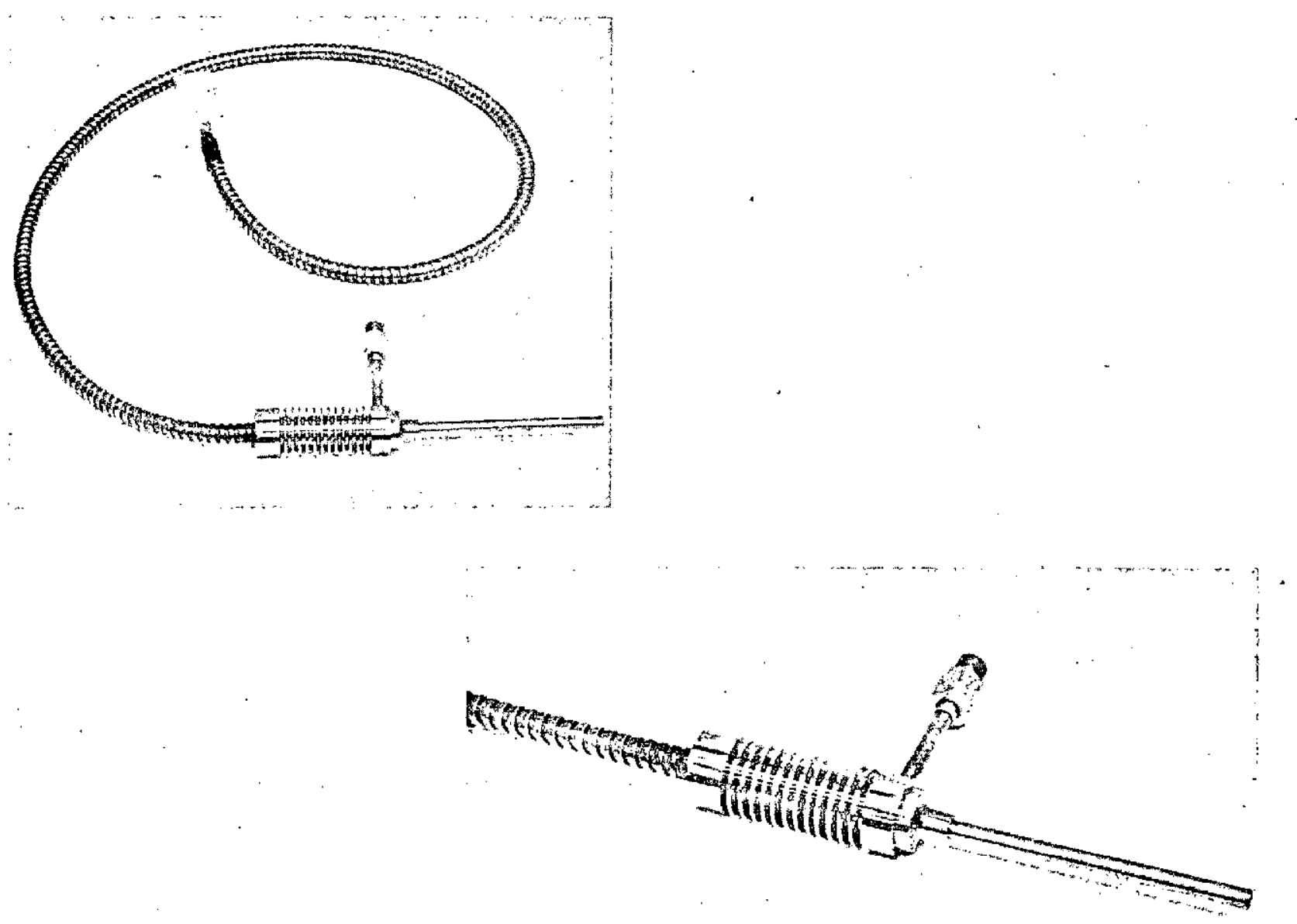

FIGURE 9. APERT URE TYPE SENSOR HEAD

typically 5 percent plus a loss of approximately 20 to 30 percent due to light that falls on the matrix of ceramic material between the individual fibers. Losses along the length of the fiber are generally 7 to 9 percent per foot of fiber length. Total loss for 2- to 3-foot bundles is thus near 60 percent. This loss is compensated for in the initial calibration of the pyrometer as long as it remains constant.

Constant transmission levels are mandatory throughout the entire system after calibration in order to realize any meaningful data from the sensor system. Because of their somewhat delicate appearance, fiber optic materials have been critized by some as undependable on gas turbine engines. However, proper understanding of the material limitations and the development of special assembly techniques have led to fiber optic assemblies that are far superior to any available two years ago. As part of this program, we have tested various fiber optic materials and assembilies. 


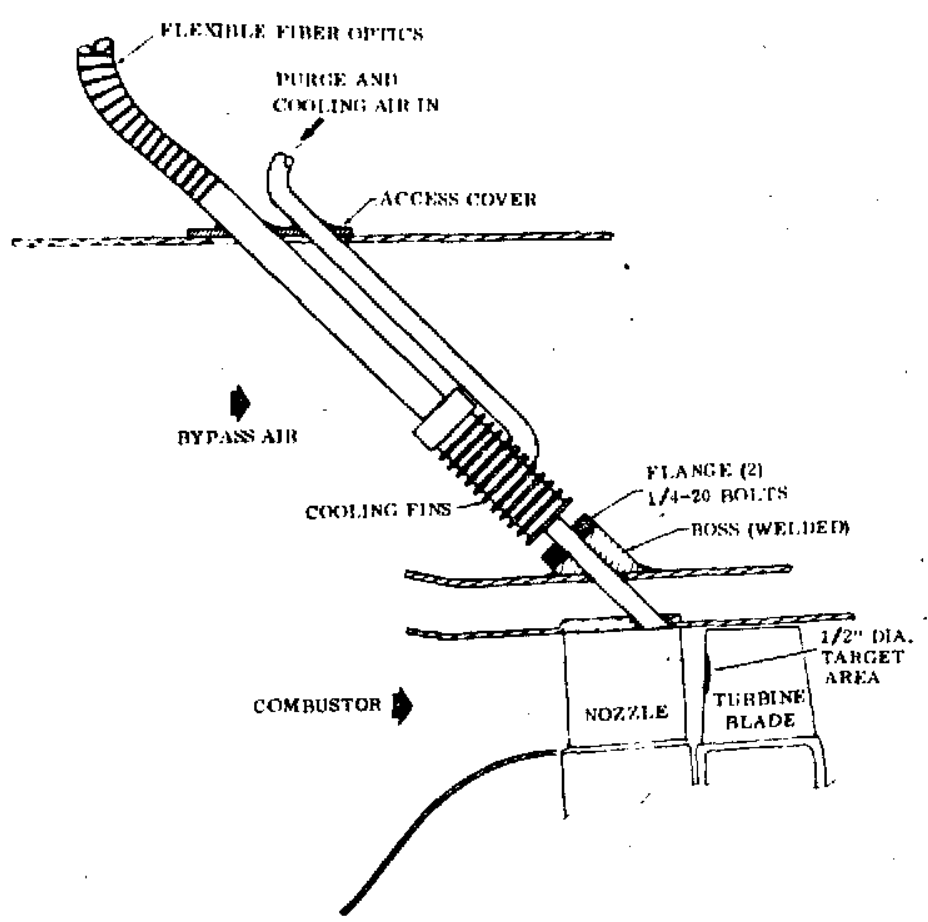

FIGURE 10. APERT URE SENSOR HEAD INSTALLED ON TF-41 TYPE ENGLNE
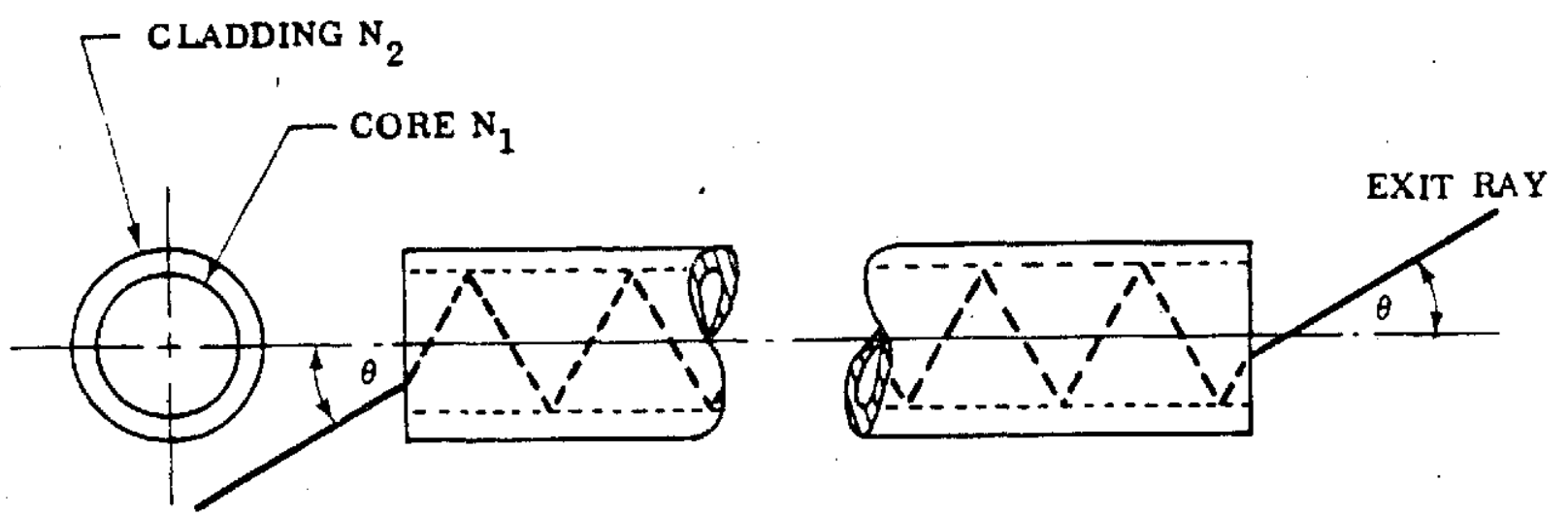

INCDENT RAY

FIGURE 11. RAY DIAGRAM FOR A COATED FIBER

\subsection{TBTMS SIGNAL CONDITIONING UNIT}

The control unit and separate silicon detector process the radiant power output from the sensor heads to obtain the most significant engineering information in this signal.

The small sensor head mounted on the turbine case collects radiant power from the first stage turbine blades as they pass across its optical path. Several feet 
of fiber optic flexible light cable then transmits the radiant power to a detector housing located remotely from the turbine case environment. The maximum detector housing operating temperature is in the 200 to $250^{\circ} \mathrm{F}$ range. Thermal compensation is provided for the detector housing by means of a thermistor mounted adjacent to the silicon photovoltaic cell. Radiant power is converted to electrical power by the detector for transmittal to the signal conditioning unit.

The signal conditioning unit incorporates the following functions:

- Amplification

- Average signal detection

- Average peak signal detection

- Maximum peak signal detection

- Temperature compensation for detector environment

- Linearization 


\section{3}

SIGNAL PROCESSOR

\subsection{GENERAL DESCRIPTION}

The signal processor accepts the signal from the silicon radiation detector and converts it into useful engineering data with a readout in millivolts directly proportional to temperature in degrees Fahrenheit $\left(1 \mathrm{mV}=1^{\circ} \mathrm{F}\right)$.

The signal processors' functions include:

- Converting the detector current signal into a voltage

-Amplifying the signal

-Compensating for thermal shift in detector output

-Filtering noise from the signal

- Detecting peak voltage

- Linearizing silicon detector output

- Display and produce output in degrees Fahrenheit

These functions are performed with the electronic hardware built into the signal processor (Solar $\mathrm{P} / \mathrm{N}$ 106751). The signal processor and its front panel design are shown in Figure 12. The operation and maintenance of this unit are described in an accompanying "Operation Manual" (Solar RDR 1752-1). The principles of the operation are described below.

\subsection{SYSTEM OPERATION}

The functional components of the signal processor and their arrangement are shown in Figure 13. An $\mathrm{N}$ on $\mathrm{P}$ silicon photovoltaic detector is the first element in this system. Photons are transduced to a microampere signal by the solid state energy converter. The output current is not only proportional to the photons (radiant power) falling on the active area, but also a function of the detector's ambient temperature. At a given input radiant power, the output of the detector increases approxmately 0.2 percent per degree $F$ rise in the temperature of the silicon itself. Thus, 

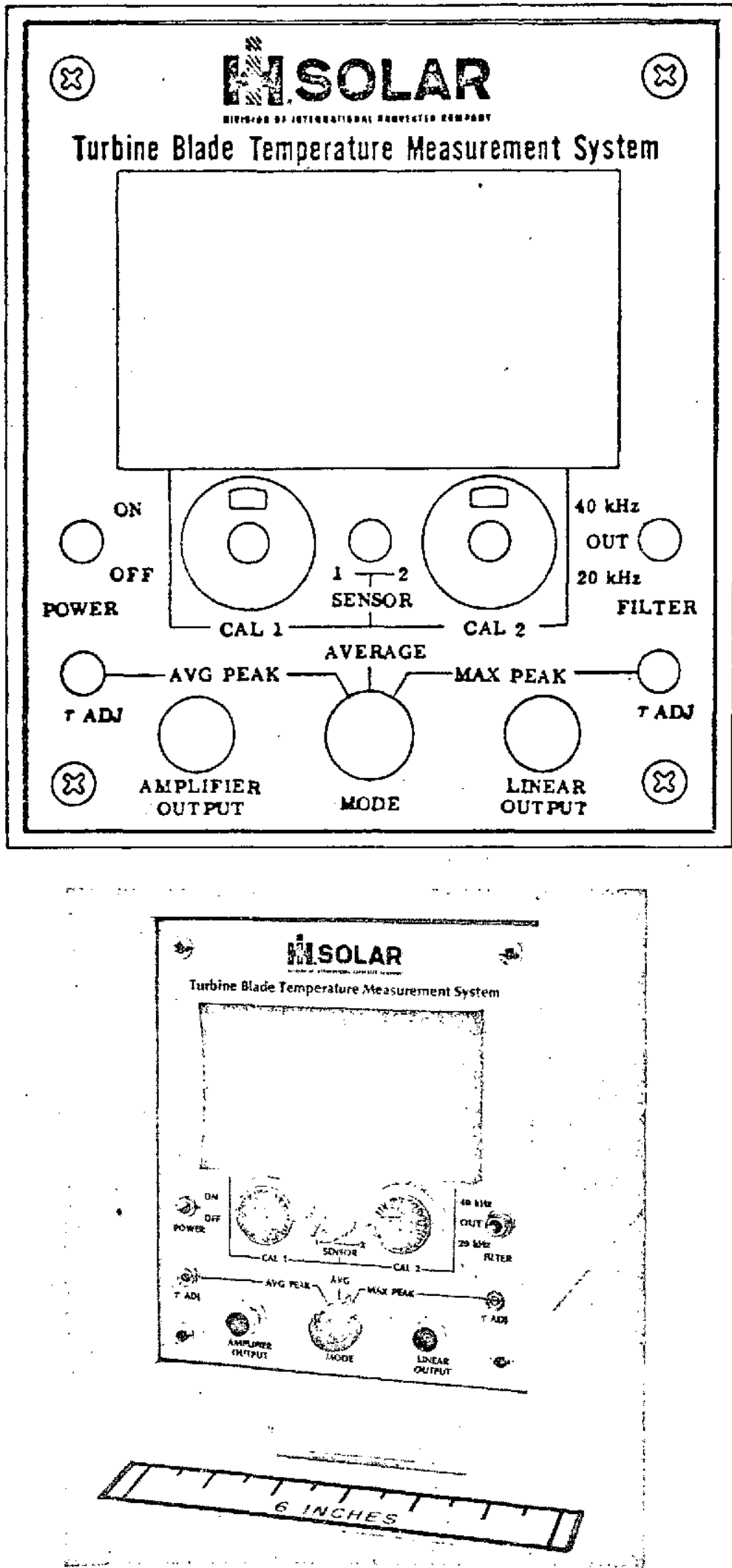

FIGURE 12. TBTMS READOUT AND CONTROL UNIT 


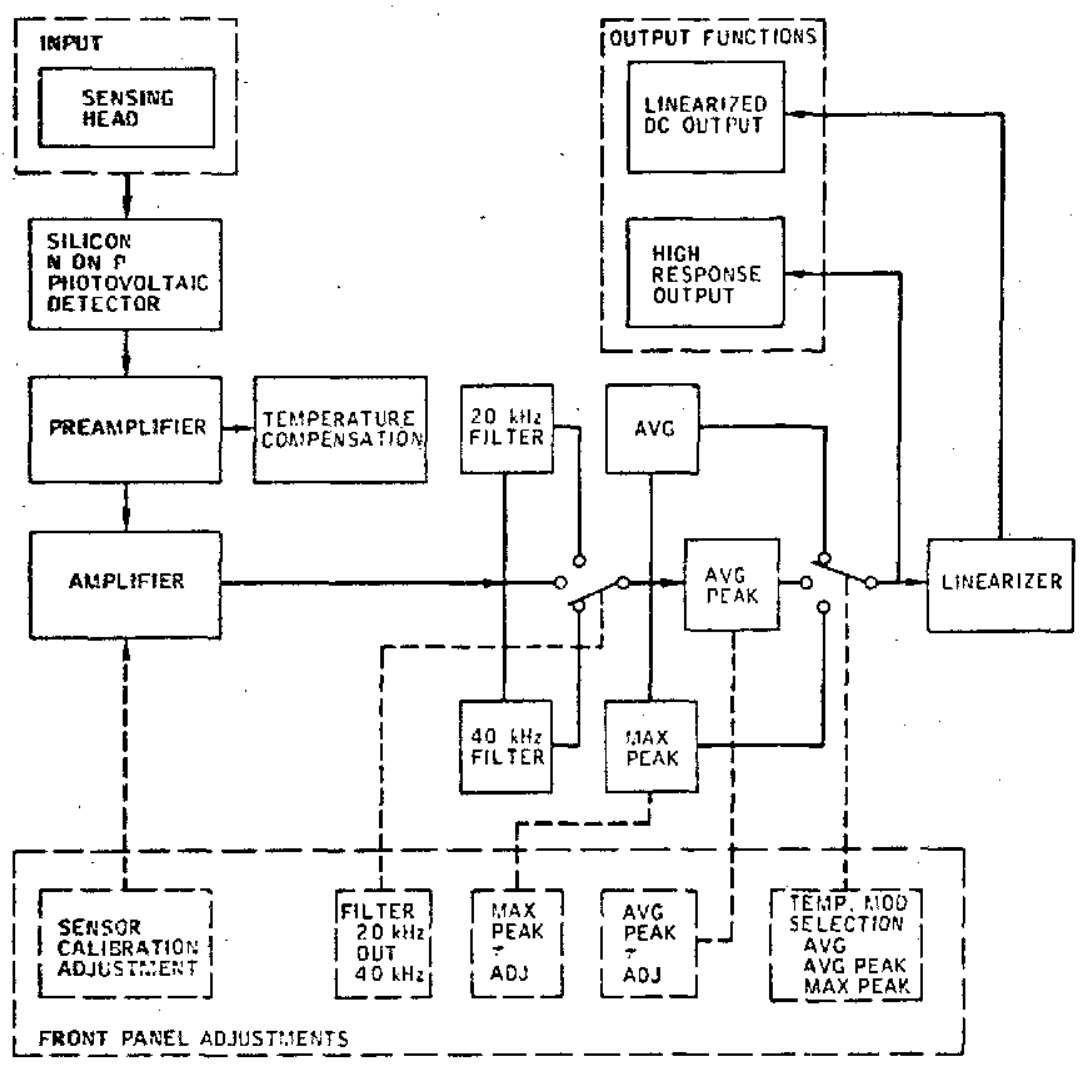

FIGURE 13. TBTMS READOUT AND CONTROL FUNCTIONAL BLOCK DIAGRAM

a sensistor is mounted to the back of a silicon detector to compensate for this temperature shift.

The current output from the detector is converted by a preamplifier to a voltage. The preamplifier, located next to the detector, has a frequency response of $25 \mathrm{kHz}$ to prevent signal attenuation at the high input frequencies resulting from blade passing rates of up to 20,000 blades per second. Normally each type of sensor head produces a different output current at a given target temperature. Thus, a gain adjustment is provided on the main amplifier that allows each sensor head to be calibrated directly in degrees $F$.

Detector thermal compensation is accomplished in the preamplifier. At this point the sensistor is connected into a feedback loop and affects the gain of that stage of amplification. Reasonable compensation $\left( \pm 10^{\circ} \mathrm{F}\right)$ is achieved for detector temperature up to $220^{\circ} \mathrm{F}$.

A three-position filter conditions the signal at the output of the compensation amplifier. Two discrete active filters ( 40 and $20 \mathrm{kHz}$ ) provide gcod noise rejection 
at frequency above the turbine blade passing frequencies. The two frequencies were chosen for laboratory test work $(20 \mathrm{kHz})$ and actual turbine operation $(40 \mathrm{kHz})$ where blade passing frequencies may exceed $20 \mathrm{kHz}$. The active filters provide a roll-off of $-12 \mathrm{db}$ per octave with no degradation in signal level for the appropriate blade passing frequencies. A "no filter" position has been provided for test purposes.

From the active filter the signal goes to the temperature mode selector switch. By positioning the switch, an average, average peak or maximum peak voltage circuit is placed in series with the rest of the system. In the ave rage circult the signal is transmitted directly to the output amplifier without further operations performed on its wave form. In the average voltage mode the peaks of the voltage wave train are held with a peak voltage hold circuit designed to maintain the voltage between each peak at approximately the average level. On Figure 14, this voltage level is shown by the interconnecting lines between each of the wave peaks representing the blade to blade output voltage. In the maximum peak temperature mode the electronic circuit switched into the system will maintain the maximum peak voltage of the hottest blade in the pulse train. The top voltage trace in Figure 14 depicts the maximum voltage level which is proportional to the blade on a wheel with the highest temperature. Each of the peak detection circuits has an adjustable hold time.

Typical turbojet turbine blade passing frequencies are as high as 20,000 blades per second, or as low as 5,000 blades per second. The basic method used to hold the voltage is to charge a capacitor through a diode and hold this voltage for a predetermined time by closed loop operational amplifier circuits. If the voltage is held for one or two milliseconds, an average peak voltage is obtained. By holding for 1000 milliseconds the maximum peak voltage will be held. Figure 14 illustrates the output of the peak hold circuits with a 3 percent drop.

The rise time of the peak circuit is about one microsecond. Thus, the current will charge to the maximum of each blade voltage pulse. As the voltage drops after reaching the peak (the blade passes out of the optical axis), the voltage is prevented from dropping by the blocking diode. A controlled discharge rate is obtained by shorting the capaciton with a high resistance variable pot. By adjusting the circuit time constant to match either turbine blade frequency passage or rotor $\mathrm{rpm}$, the circuits can be made to hold a voltage proportional to average blade temperature or hottest blade temperature.

Typical response of the signal output for each mode is as follows:

AVG, T $<10 \mu \mathrm{sec}$

AVG PEAK, $T \cong 1$ to $3 \mathrm{msec}$

MAX PEAK, $T \cong 50$ to $200 \mathrm{msec}$ 


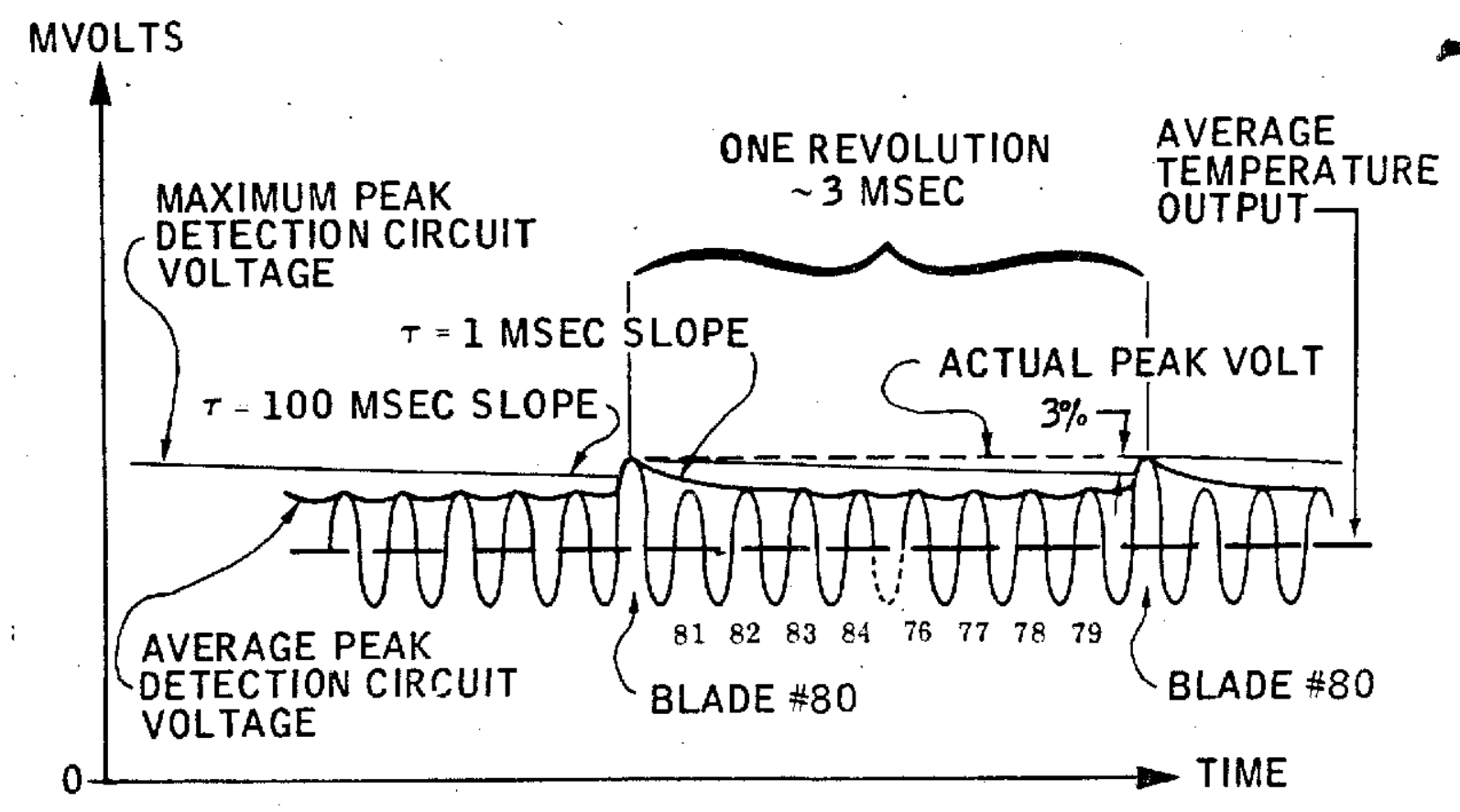

FIGURE 14. VOLTAGE DETECTION AND ANALYSIS CIRCUIT OUTPUTS

The signal output of the amplifier and mode control is highly nonlinear with temperature. A 'high response" output at this point allows the operator to view the actual waveform which is similar to that in Figure 14. Intelligent interpretation of this display can help in diagnosis or development work on gas turbine engines. For control and visual interpretation it is useful to have a linear output directly proportional to turbine blade temperature. The components following the amplifier perform these functions. The linearizer produces a signal proportional to temperature $\left(1 \mathrm{mV}=1^{\circ} \mathrm{F}\right)$ in the range $1400^{\circ} \mathrm{F}$ to $2200^{\circ} \mathrm{F}$. Linearizer response time is less than $5 \mathrm{msec}$. At this stage the signal can be diverted to either display units, used in an engine control scheme or both.

\section{3 DETECTORS}

The silicon detectors used in the TBTMS must be rugged and small, and have high frequency response and linear thermal drift characteristics. No one detector brand has all of the desired features. The two most important tests, temperature drift and frequency response, have been performed on detectors from four or more manufacturers. These detectors all had the same spectral response but varied in construction from unmounted to completely encased. They were tested for frequency response and thermal drift. It has been found through experience that the unmounted detectors are the smailest and most rugged, especially when custom mounted into the preamplifier assembly. Factory mounted detectors are not assembled for use over a wide temperature range. Most of these detectors fall at extreme temperatures due to bonding, wiring and mounting problems. 


\subsection{PREAMPLIFIERS}

The concept of building a preamplifier into the detector housing to increase the line driving power and noise suppression has been employed. Each sensor head has a builtin detector-preamplifier that is individually temperature compensated up to $220^{\circ} \mathrm{F}$. No further adjustments can be made.

\subsection{HYBRID CIRCUITS}

The linearizer, filter and peak circuit have been miniaturized using thinfilm hybrid circuit techniques. (Halex, Inc. of Torrence, California has built the units according to the required circuits and specifications.) In this method the resistors and connections are formed with deposits of nickel-chrome alloy and gold respectively. The monolithic amplifiers and tantalum chip capacitors are bonded to the substrate and connected to the circuit with gold or aluminum wires. The TBTMS circuits are on . a mounting platform similar to that shown in Figures 15 and 16.

One unit contains a TBTMS linearizer which operates over the blade temperature range of 1400 to $2200^{\circ} \mathrm{F}$. Eight operational amplifiers, 12 diodes, 38 resistors, and one capacitor are included in the one hybrid circuit can. Four of these units were checked for accuracy. In a pre-program test, a series of standard input voltages was applied to the input of each unit and the corresponding output recorded. A precision voltage source was used to generate the input. A summary of the data is shown in Table III. One linearizer was also tested at -50 and $+100^{\circ} \mathrm{C}$ to check its operation under a wide temperature range. At room temperature each unit was within $\pm 10^{\circ} \mathrm{F}$ of the desired output. At high temperatures, Unit \#1 produced outputs that ranged from 11 to $39^{\circ} \mathrm{F}$ above the standard temperature. At $-50^{\circ} \mathrm{C}$ the outputs were $2-14^{\circ} \mathrm{F}$ below the standard temperatures. The performance at room temperature was very good. The performance at the other temperatures was not unreasonable.

The filter and peak circuits have been included together on another circuit platform. This unit is composed of 4 amplifiers, 1 transistor, 4 diodes, 12 resistors, and 8 capacitors. The amplifiers in this unit are of the low-drift variety and are rated to operate from -50 to $+125^{\circ} \mathrm{C}$. Tests have shown that both circuits operate as planned and there are no problems. The $40 \mathrm{kHz}$ filter has been tested for frequency response. The result of this test is shown in Figure 17.

\subsection{SYSTEM DESIGN}

The complete TBTMS signal processor has been built using the components described above. The preamplifiers are used as individual components, and the hybrid circuits have been incorporated into a one-board TBTMS shown in Figure 18. This unit contains the separate $20 \mathrm{kHz}$ filter, amplifiers and hybrid chips. Including the extra hardware, the complete signal processor fits on a $4 \times 4$ inch circuit board with more than ample room. 


\begin{tabular}{|c|c|c|}
\hline \multicolumn{3}{|c|}{ TABULATION BLOCK } \\
\hline \multicolumn{2}{|c|}{-2} & \\
\hline$A$ & $1250 \pm .00$ & \\
\hline$B$ & $1.100 \pm .005$ & \\
\hline$C$ & $100 \pm .005$ & \\
\hline$D$ & $600 \pm .005$ & \\
\hline$E$ & $750 \pm .005$ & \\
\hline$F$ & $040 \pm .005$ & \\
\hline$G$ & $015 \pm .005$ & \\
\hline$H$ & $015 / .020$ & \\
\hline$J$ & $050 \pm .005$ & \\
\hline$K$ & $295 \pm .005$ & \\
\hline
\end{tabular}

\section{NOTE}
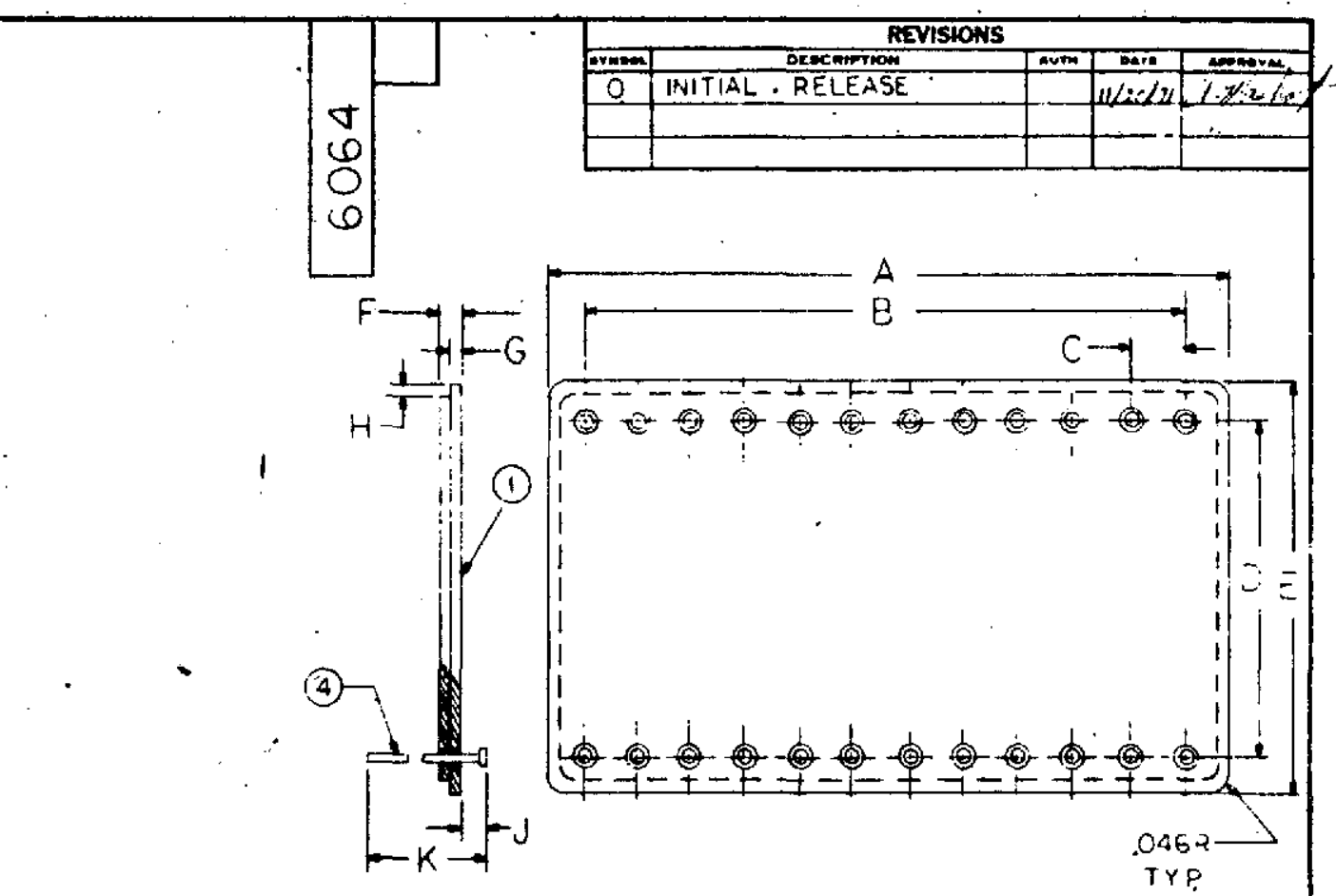

(1) Flat WITHIN .005 TIR

(2) Material SHaLl be Kovip AVD PLATING SHALL BE PER MIL-G-45204 TYPE I CLASSI

(3) hol. non accumulative

(4) OIB DIA. KOVAR

•

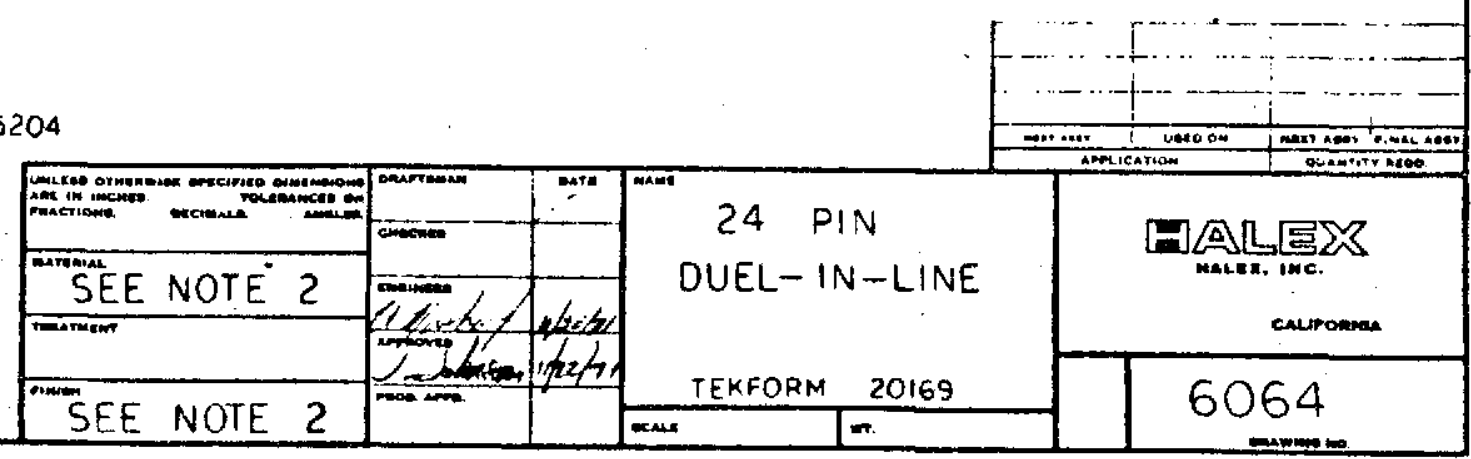

FIGURE 15. PLAT FORM FOR HYBRID CIRCUITS - TWO ARE EMPLOYED 


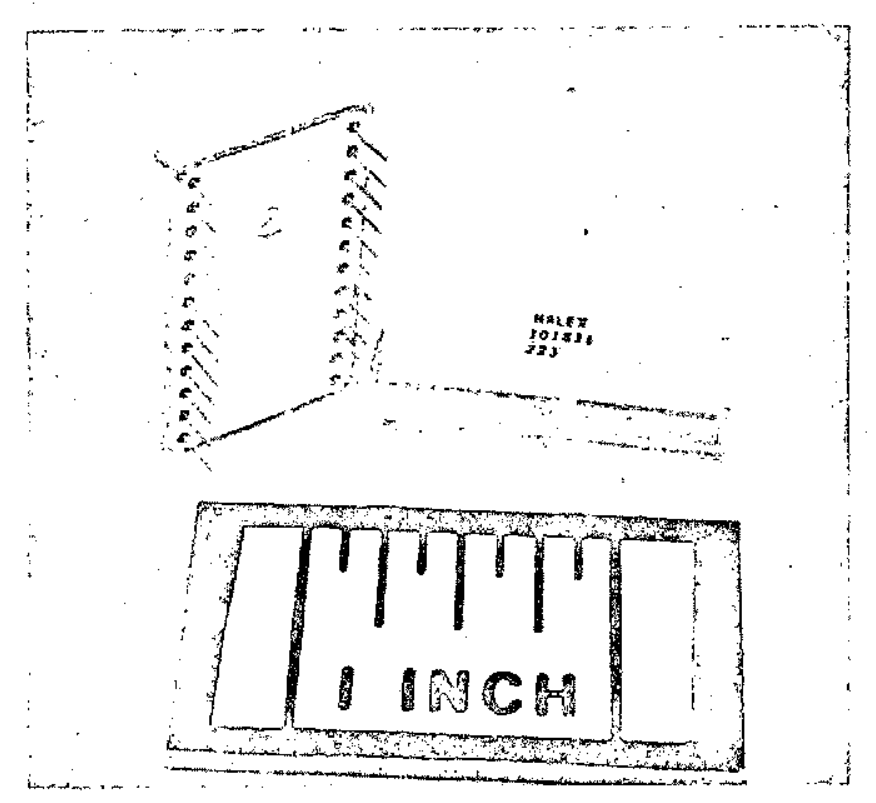

FIGURE 16. HYBRID CIRCUIT PACKAGE. TWO ARE USED IN EACH SIGNAL PROCESSOR

TABLE III

HYBRD LINEARIZER TESTS*

\begin{tabular}{|c|c|c|c|c|c|c|c|}
\hline \multirow{3}{*}{$\begin{array}{c}\text { Input } \\
\text { mV }\end{array}$} & \multirow{3}{*}{$\begin{array}{r}\text { Operating } \\
\text { Temp. } \\
\text { Temp. }{ }^{\circ} \text { F }\end{array}$} & \multicolumn{6}{|c|}{ Output (mV) } \\
\hline & & \multicolumn{4}{|c|}{$25^{\circ} \mathrm{C}$} & \multirow{2}{*}{$\frac{-50^{\circ} \mathrm{C}}{\# 1}$} & \multirow{2}{*}{$\frac{+100^{\circ} \mathrm{C}}{\# 1}$} \\
\hline & & . $\# 1$ & $\# 2$ & $\# 3$ & $\# 4$ & & \\
\hline 0 & 1300 & 1299 & 1299 & 1300 & 1299 & 1294 & 1308 \\
\hline 64.56 & 1340 & 1363 & 1364 & 1364 & 1363 & 1359 & 1372 \\
\hline 103.42 & 1400 & 1402 & 1402 & 1402 & 1402 & 1398 & 1411 \\
\hline 139.63 & 1440 & 1438 & 1439 & 1438 & 1438 & 1434 & 1411 \\
\hline 214.65 & 1500 & 1504 & 1501 & 1502 & 1502 & 1498 & 1516 \\
\hline 282.20 & 1540 & 1537 & 1535 & 1536 & 1536 & 1531 & 1650 \\
\hline 417.46 & 1600 & 1605 & 1603 & 1603 & 1604 & 1599 & 1617 \\
\hline 535.52 & 1640 & 1638 & 1640 & 1637 & 1638 & 1630 & 1654 \\
\hline 765.01 & 1700 & 1698 & 1701 & 1698 & 1699 & 1691 & 1715 \\
\hline 960.07 & 1740 & 1741 & 1742 & 1735 & 1738 & 1731 & 1760 \\
\hline 1329.96 & 1800 & 1800 & 1801 & 1797 & 1798 & 1790 & 1821 \\
\hline 1637.75 & 1840 & 1840 & 1844 & 1840 & 1839 & 1829 & 1863 \\
\hline 2210.77 & 1900 & 1897 & 1898 & 1896 & 1897 & 1886 & 1921 \\
\hline 2680.64 & 1940 & 1943 & 1.943 & 1942 & 1945 & 1932 & 1968 \\
\hline 3545.77 . & 2000 & 2000 & 1996 & 1996 & 1998 & 1989 & 2027 \\
\hline 4250.10 & 2040 & 2045 & 2038 & 2038 & 2040 & 2034 & 2073 \\
\hline 5543.18 & 2100 & 2099 & 2098 & 2096 & 2095 & 2098 & 2128 \\
\hline 6597.07 & 2140 & 2137 & 2137 & 2133 & 2135 & 2127 & 2167 \\
\hline 8543.01 & 2200 & 2206 & 2207 & 2203 & 2209 & 2198 & 2239 \\
\hline
\end{tabular}

*Performed under Contract N00019-71-C-0288 


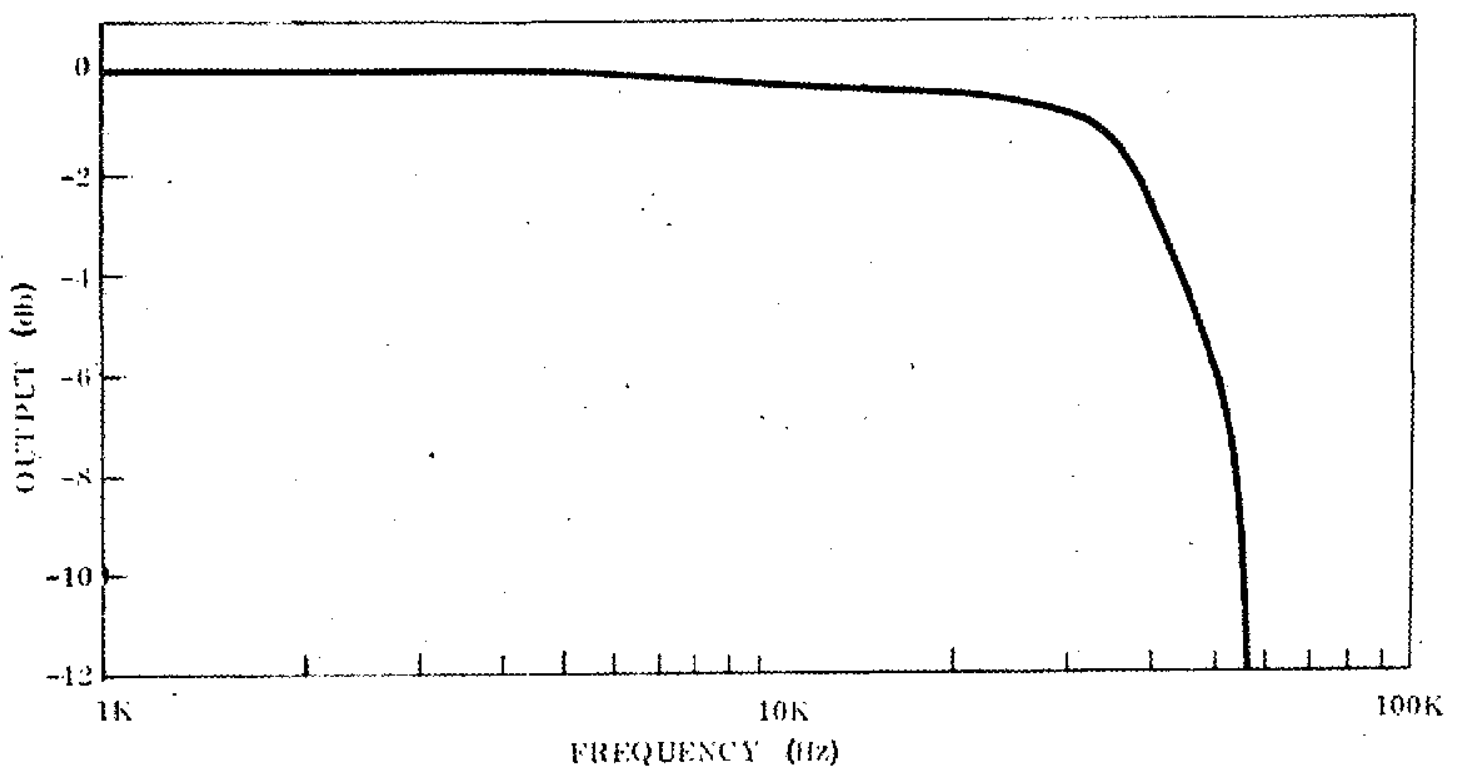

FIGURE 17. FREQUENCY RESPONSE OF HYBRID FLLTER

(Test Performed Under Contract No0019-71-C-0288)

\subsection{CALIBRATION}

System calibration throughout this program has been tested using the equipment depicted in Figure 19. The TBTMS is assembled as a complete system and the sensor head placed an appropriate distance from the target. The target temperature is recorded with the temperature indicated on the digital panel meter of the signal processor. Deviations are noted.

The target is an electrically heated strip of Inconel. Target temperature is well regulated with a solid state controller using a Pt-Pt13\%Rh thermocouple as a temperature sensor. An independent system composed of a potentiometer, null detector and separate thermocouple is used to monitor the target temperature. Periodic comparisons are made with a calibrated disappearing filament pyrometer. When end-to-end calibrations are performed, sufficient time is allowed at each temperature plateau to permit the thermocouple junction and target to achieve thermal equilibrium. Details of other calibration methods are found in the Operation Manual (Solar RDR 1752-1). Specific calibrations of the units delivered under this program are found in Section 5 of this report. 


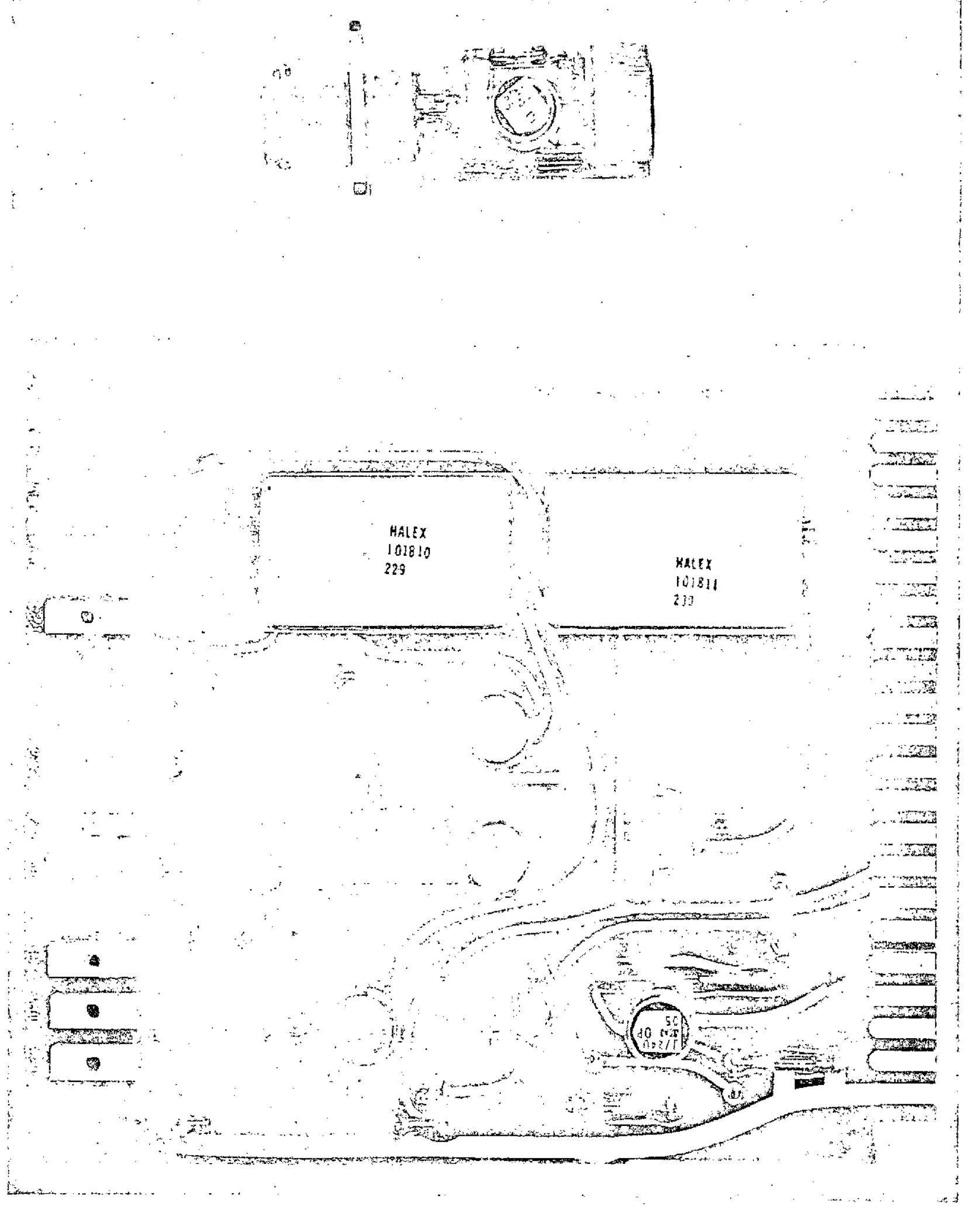

FIGURE 18. CIRCUTT BOARDS USED IN TBTMS 


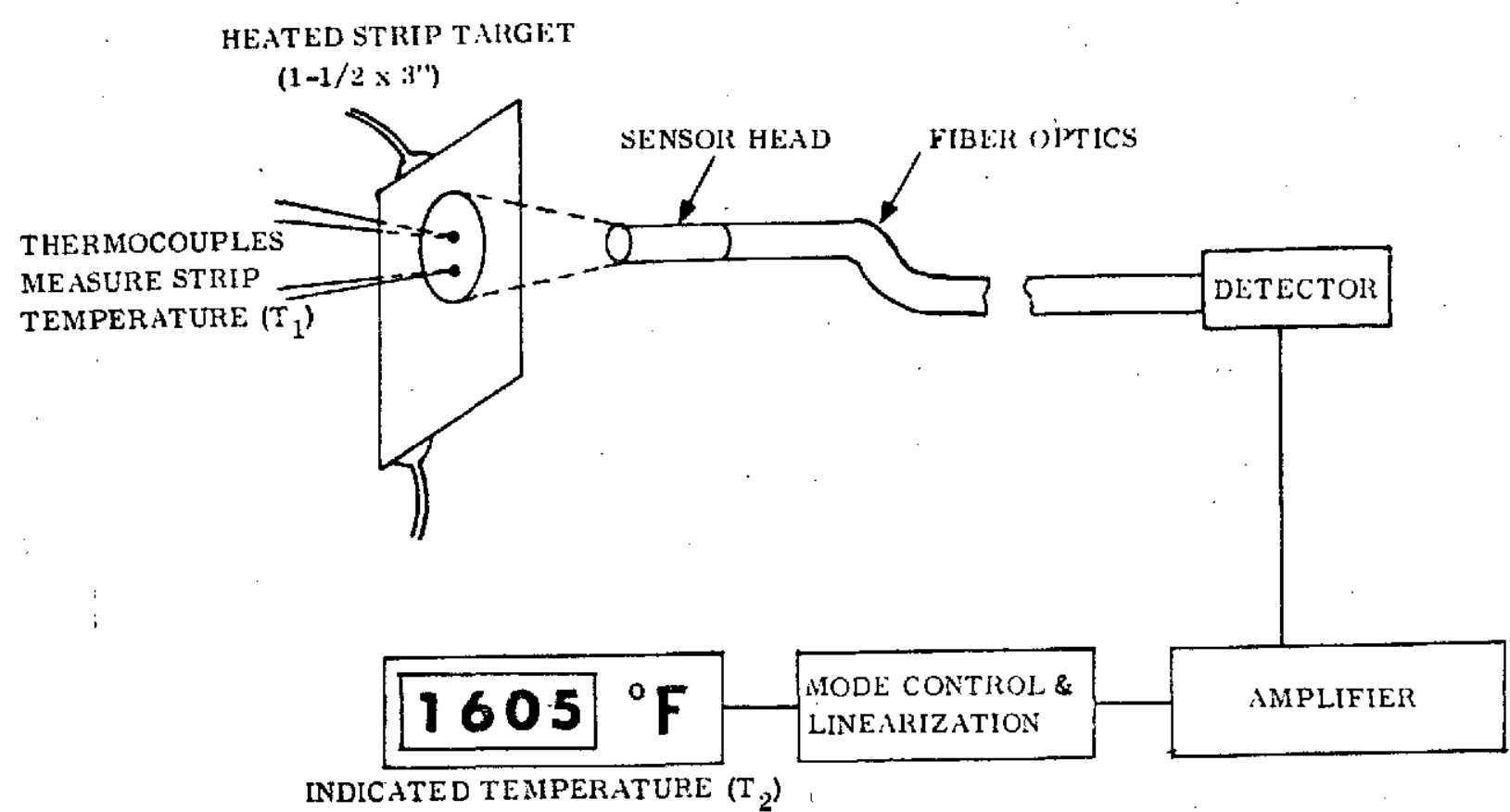

FIGURE 19. DIAGRAM OF END-TO-END CALIBRATION TEST . 


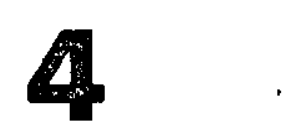

\section{SENSOR HEAD AND OPTICS}

The purpose of the optical system is to define the target area on the surface of the blades and to direct the radiant energy onto the detector. Remote placement of the detector due to its limited temperature capabilities makes the use of a light pipe or fiber optic bundle necessary. The sensor head holds the objective end of the optical system in the proper geometric relationship to the target and provides an interface between the optics and the engine including purge air to maintain the objective window clean. While the basic optical system has been developed, particular problems were approached in the current work. The solutions to these problems will enable the TBTMS to be more widely used and more accurate in its operation. A brief introduction to the optical system is given in the paragraphs below.

\subsection{OPTICAL SYSTEM}

There are two basic types of optical systems applicable to turbine blade temperature measurement systems. Figure 6 shows a schematic diagram of lens and light pipe optical systems with the principal environmental temperature zones imposed by the engine. A lens system, Figure $6 \mathrm{~A}$, uses an objective lens to focus the radiation onto a field aperture which defines the target size and shape. The radiation is then transmitted to the cooled detector by a solid light pipe, flexible fiber optic bundle or combination of the two types. Typical objective aperture diameter is 0.04 -inch with 0.25 to 0.7 inch target diameters. Figure $6 \mathrm{~B}$ shows a light pipe system where the radiation falls directly upon the light pipe or flexible fiber optic bundle. Radiation is accepted by the light pipe within a cone of half angle usually equal to 10 to 11 degrees, thus defining a target area on the blade surface. From geometrical effects, the target is less well defined than with a lens; there is a diffuse ring around the control target area from which radiation is only partially accepted. In comparison with the lens system, the objective aperture of a light pipe system is small, typically 0.040 inch diameter, and the target area is large, 0.3 to 0.5 inch. The temperature imposed on each section of the optics is shown in Figure 6.

\subsection{EFFECTS OF ENGINE ENVIRONMENT ON DATA}

The optical system mounts directly on the engine case and receives radiation from the hot turbine blades for transmittal to the solid state detector. Previous work 
has shown that the optical sensor can create sufficient self-radiation above $750-800^{\circ} \mathrm{F}$ to effect the accuracy of the TBTMS. This problem is overcome with the use of purge

air. Another spurious signal source that enters into the system through the optical system is thermal radiation emitted from an internal engine part, such as a seal, and reflected by the blade into the sensor. This radiation is in addition to the normal thermal radiation produced by the turbine blade and is only important when a large area near the sensor is hotter than the blade. In most cases, the hardware near the blades, e.g., seals, stator vanes, and root assemblies, is the same temperature or cooler than the turbine blade. One can use standard calculation to assess this effect, if it is important.

\subsection{DESCRIPTION OF SENSOR HEADS}

The two types of sensor heads, aperture and lens, delivered as part of this program, are shown in Sheet 1 and 2 of Solar Drawing 106796 (see Figs. 20 and 21). The aperture sensor is shown in that drawing as the -0 assembly, while the lens type sensor is shown as the -100 assembly. The heads are identical in detail 13 through 18 including detail 11. For that reason the -100 assembly is shown only where it differs from the -0 assembly.

Both sensor heads share a common body section and purge air tube. The heads may be installed and seated on the K-seal with the use of an appropriate wrench on the machined flats on the bodies. The purge air tube may be flared or modified to accept a connector that is common to the user's system. The tube is 321 stainless steel, $1 / 4$ inch O.D. $\times 0.028$ inch wall. .

The long tube protruding from the body of the aperture sensor contains a solid fiber optic rod and the optical acceptance aperture. This tube should not be bent nor should it be subjected to high impact. Under almost all engine conditions this tube is not endangered. Rough handling, however, may result in damage. The aperture at the tip of the sensor is cooled and protected against sooting by the purge air that flows through it and around it. It is important that the aperture assembly does not exceed $900^{\circ} \mathrm{F}$. . Spurious signals will be generated by the aperture assembly at that temperature, resulting in inaccurate data. Compressed air or nitrogen can be used as a purge air supply in general installations. Because the turbopump runs hydrogen rich, it is recommended that an inert gas such as argon be used to purge both sensor head types. The aperture sensor has an internal sapphire window which separates the solid fiber optics from the flexible cable. The window is brazed into the sensor and forms a pressure seal between the purge air cavity and the flexible fiber optics which can leak small quantities of the purge gas.

The lens sensor incorporates a sapphire lens, 0.5 inch in diameter, that is brazed into the sensor in such a manner to seal the fiber optic cable from the purge 


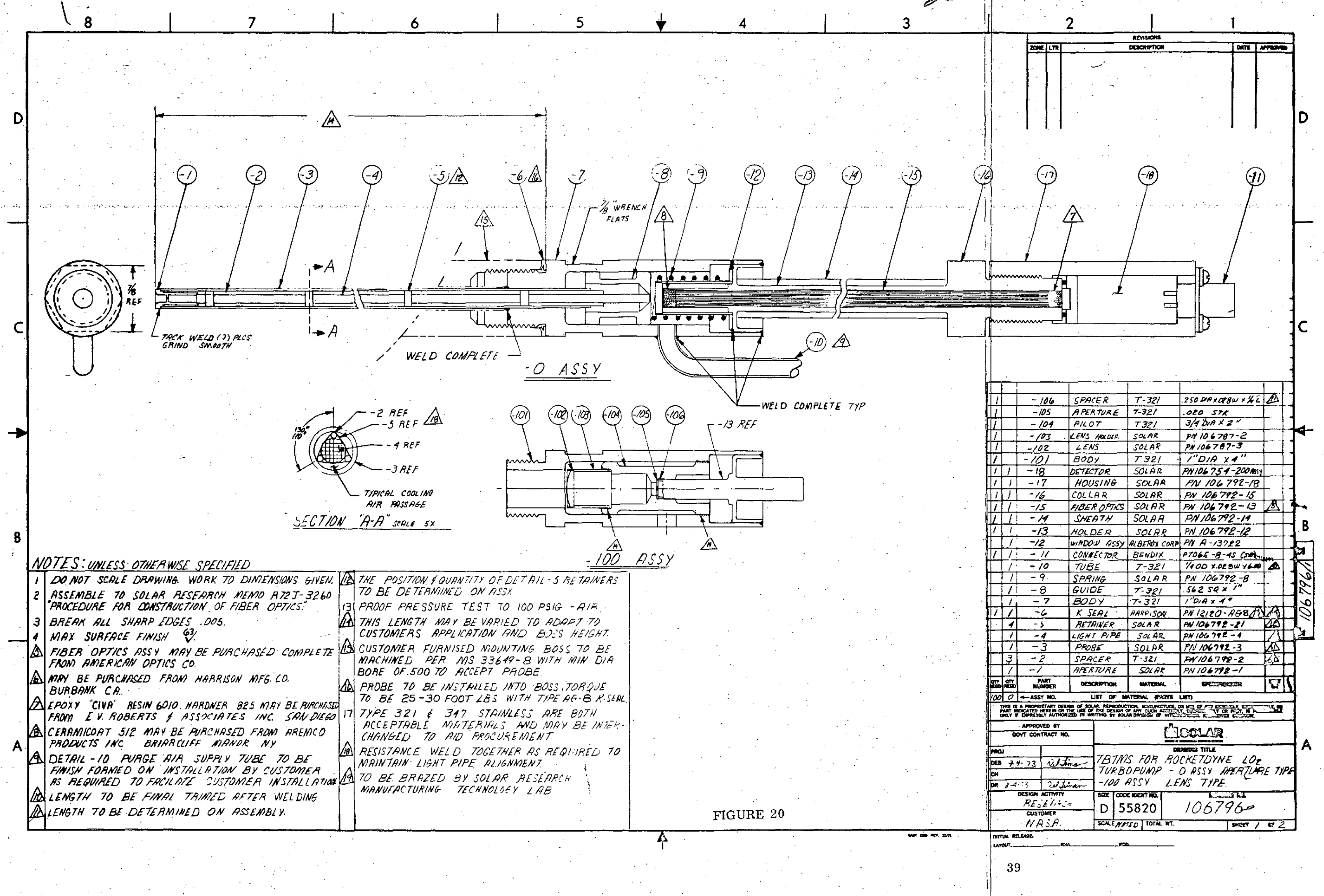


जnt

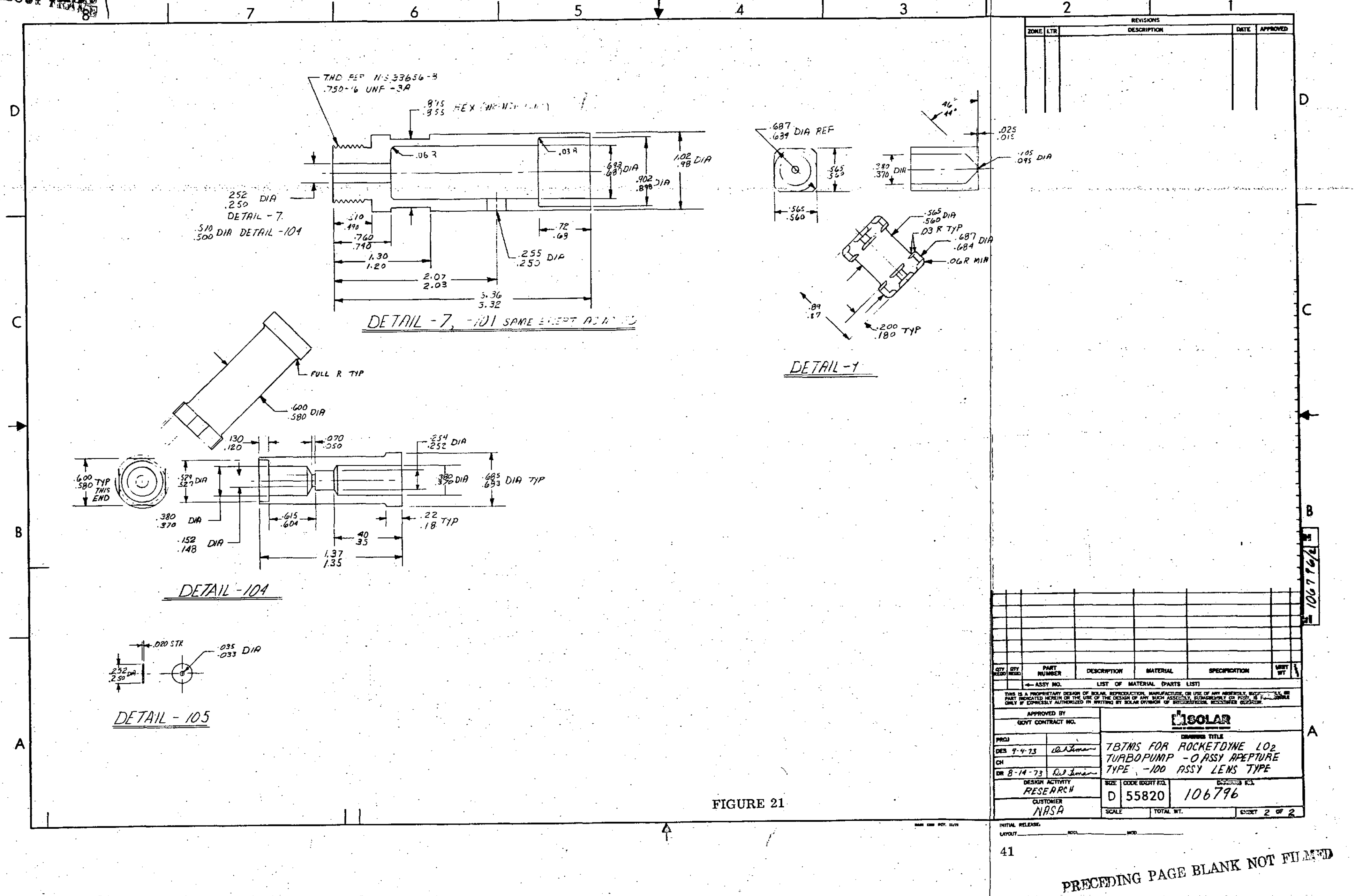


air. Lens cleanliness is maintained with the use of directed purge air which enters the side of the body, flows around the lens holder and subsequently is directed across the face of the lens. An aperture in the lens sensor, detail 105, is used to select the appropriate target area on the turbine blade. The fiber optic cable accepts the thermal radiation that passes through the aperture and transmits it to the detector-preamplifier assembly.

\subsection{FIBER OPTIC CABLES}

Flexible fiber optic cables are an essential part of the entire sensor system under development. It is these cables which transmit the radiant energy collected by the sensor heads to the silicon radiation detector. The cables allow the system designer to place the temperature sensitive silicon detector at a position of relatively low temperature and thus avoid the serious problems associated with a fuel cooled detector system. Fiber optics has received greatly increased acceptance during the past year because of the fuel cooling problems.

Since the flexible bundles are composed of thousands of individual glass fibers, some people are inclined to think of these cables as fragile laboratory instruments not usable in the harsh environment of a gas turbine engine. Until recently, criticism of this type may have been well founded due to a lack of commercially available assemblies that could withstand engine conditions. The fiber optic cables used in the delivered system were fabricated at Solar. Extensive testing of these. cables (performed in a preceding program) has shown that careful attention to detail and proper assembly techniques can result in fiber optic cables with a long lifetime under adverse conditions.

\subsubsection{Fiber Optic Material}

Fiber optic cables are composed of many thousands of clad glass fibers. Each fiber, about 0.003 inch in diameter, is composed of an inner glass core and a glass cladding made from a glass with a different index of refraction. Light entering the core glass is transmitted in the manner described in Section 2.7. The transmission of the cable as a whole is determined by packing density of the glass fibers at the ends of the cable. Obviously, areas that contain no fibers transmit no light or radiant energy. Neither is light incident on the cladding glass of each fiber transmitted. Thus, high packing density is very important in achieving measurable signal levels.

The flexible glass fibers which compose the cable are not attached to each other over the entire length except at each end At those positions the fibers are collected into a metal ferrule and cemented into place. It is at these points where cable quality is evident. Good pack densities and long life of the cable are determined 
by the process of cementing fibers into the ferrules. Due to the temperature requires ments of the detector, the end of the fiber optic cable which is closest to the detector remains cool (under $300^{\circ} \mathrm{F}$ ) and presents no difficult assembly problems. The other end of the cable must operate near the engine and thus sustain temperatures that approach 800 to $1000^{\circ} \mathrm{F}$, depending on the particular engine and sensor installation. The glasses used in the fiber optics must not soften at these temperatures nor should they separate from or be attacked by the binding material that holds them in the ferrule. For this reason, the glasses employed in the cables are high-temperature glasses, $1400^{\circ} \mathrm{F}$ softening temperatures. Careful assembly procedure has enabled us to avoid glass-ferrule separations that often cause the premature failure of commercial cables. After thousands of hours of testing at $900^{\circ} \mathrm{F}$, all cables built at Solar have retained a very flat end surface and exhibit no tendency toward separations. High pressure and vibration levels at elevated temperature have failed to destroy the integrity of these cables. This should not be interpreted in such a manner as to imply that the cables are impenetrable at high pressures. The cables were tested at $400 \mathrm{psig}$ and all exhibited some gas passage along the direction of the fibers. Such leakage is almost immeasurable in some cases.

\subsubsection{Fiber Optic Cable Preparation}

All fiber optic cables are carefully polished at each end to achieve a flat surface. The end surfaces should be mounted parallel to the detector surface at the cool end and perpendicular to the optical axis of the sensor head at the hot end. Maximum acceptance of the radiation and a maximum transfer of that energy to the detector are achieved in that way.

After installing the ferrules and polishing the end surfaces, the cable assembly is completed with the addition of a protective sheath. For laboratory systems, this sheath has been flexible, spiral wound, stainless steel tubing. This allows for maximum flexibility in various situations. For flight applications, the fiber optic sheath should be composed of a rigid thin wall stainless tubing. Tubing of this type would allow the system designers more freedom in routing and attaching the cable and assure him that the cable would remain in the desired location. Large movements of the glass fibers would be avoided, reducing the chance of accidental breakage. The fiber optic cables would be built into preformed tubing sections with the ferrules secured to the tubing.

\subsection{INSTALLATION}

An installation drawing, Solar 106797, was delivered with the signal processor and sensor heads. That drawing shows the suggested mounting position and suggested customer supplied mounting boss. Both types of sensor heads have been designed to fit the same mounting boss. 


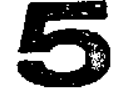

\section{CALIBRATION TESTS}

The entire TBTMS was assembled and tested for each of the four sensor heads delivered. The calibration device was an electrically heated strip target previously described in this report. The emissivity of that target is about 0.85 . The experimental conditions and system gain setting are shown in the top of Tables IV through VII for each sensor head. The digital display for each of the calibration temperatures is shown in the botlom part of these tables. Under laboratory conditions, the deviation from the set point was no greater than $5^{\circ} \mathrm{F}$. 
TABLE IV

SOLAR TBTMS

INSTRUMENT CALIBRATION

\section{SENSOR HEAD NUMBER 0-1}

The sensor head(s) and control unit have been calibrated prior to shipment.

Part Number
Serial Number
Sensor-to-Target Distance
Target Area Diameter
"Sensor Calibration" Gain Setting
"Sensor Calibration" Adjusted at

Accuracy

Target Digital

Temperature Readout

$\begin{array}{ll}1400^{\circ} \mathrm{F} & 1405 \\ 1500^{\circ} \mathrm{F} & 1500 \\ 1600^{\circ} \mathrm{F} & 1600 \\ 1700^{\circ} \mathrm{F} & 1698 \\ 1800^{\circ} \mathrm{F} & 1799 \\ 1900^{\circ} \mathrm{F} & 1899 \\ 2000^{\circ} \mathrm{F} & 2003\end{array}$
106796
0-1
5.43 inches
0.150
4.10
$1600^{\circ} \mathrm{F}$

\section{TABLE V}

SOLAR TBTMS

INSTRUMENT CALIBRATION

\section{SENSOR HEAD NUMBER 0-2}

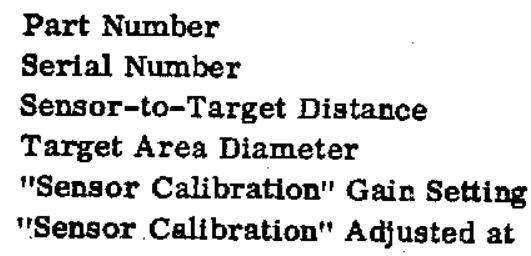

\section{Accuracy}

Target Digital

Temperature Readout

$\begin{array}{ll}1400^{\circ} \mathrm{F} & 1400 \\ 1500^{\circ} \mathrm{F} & 1500 \\ 1600^{\circ} \mathrm{F} & 1600 \\ 1700^{\circ} \mathrm{F} & 1700 \\ 1800^{\circ} \mathrm{F} & 1799 \\ 1900^{\circ} \mathrm{F} & 1900 \\ 2000^{\circ} \mathrm{F} & 1998\end{array}$

\author{
106796 \\ 0-2 Aperture \\ 5.43 inches \\ 0.150 \\ 3,65 \\ $1600^{\circ} \mathrm{F}$
}




\section{TABLE VI \\ SOLAR TBTMS \\ INSTRUMENT CALIBRATION \\ SENSOR HEAD NUMBER 100-1}

The sensor head(s) and control unit have been calibrated prior to shipment.

\begin{tabular}{|c|c|c|}
\hline \multicolumn{3}{|c|}{$\begin{array}{l}\text { Part Number } \\
\text { Serial Number } \\
\text { Sensor-to-Target Distance } \\
\text { Target Area Diameter } \\
\text { "Sensor Calibration" Gain Setting } \\
\text { "Sensor Calibration" Adjusted at }\end{array}$} \\
\hline & \multicolumn{2}{|c|}{ Accuracy } \\
\hline & $\begin{array}{c}\text { Target } \\
\text { Temperature }\end{array}$ & $\begin{array}{l}\text { Digital } \\
\text { Readout }\end{array}$ \\
\hline & $1400^{\circ} \mathrm{F}$ & 1400 \\
\hline . & $1500^{\circ} \mathrm{F}$ & 1500 \\
\hline & $1600^{\circ} \mathrm{F}$ & 1600 \\
\hline & $1700^{\circ} \mathrm{F}$ & 1696 \\
\hline & $1800^{\circ} \mathrm{F}$ & 1798 \\
\hline 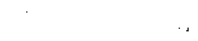 & $1900^{\circ} \mathrm{F}$ & 1898 \\
\hline & $2000^{\circ} \mathrm{F}$ & 2001 \\
\hline
\end{tabular}
106796
100-1 Lens
5.43 inches
0.150
3.05
$1600^{\circ} \mathrm{F}$

\section{TABLE VII \\ SOLAR TBTMS \\ INSTRUMENT CALIBRATION}

SENSOR HEAD NUMBER 100-2

Part Number

Serial Number

Sensor-to-Target Distance

Target Area Diameter

"Sensor Calibration" Gain Setting

"Sensor Calibration" Adjusted to
106796

100-2 Lens

5.43 inches

0.150

3.75

$1600^{\circ} \mathrm{F}$

\begin{tabular}{|c|c|}
\hline \multicolumn{2}{|c|}{ Accuracy } \\
\hline $\begin{array}{c}\text { Target } \\
\text { Temperature } \\
\end{array}$ & $\begin{array}{r}\text { Digital } \\
\text { Readout }\end{array}$ \\
\hline $1400^{\circ} \mathrm{F}$ & 1400 \\
\hline $1500^{\circ} \mathrm{F}$ & 1499 \\
\hline $1600^{\circ} \mathrm{F}$ & 1600 \\
\hline $1700^{\circ} \mathrm{F}$ & 1697 \\
\hline $1800^{\circ} \mathrm{F}$ & 1800 \\
\hline $1900^{\circ} \mathrm{F}$ & 1898 \\
\hline $2000^{\circ} \mathrm{F}$ & 2001 \\
\hline
\end{tabular}




\section{REFERENCES}

1. Duffy, T. E., et al, "Research Analysis of Advanced Sensors for Turbine Inlet Gas Temperature"t, prepared by Solar Division of International Harvester Company under contract N00019-69-C0574 for the Department of the Navy, Naval Air Systems Command (October 1970).

2. Duffy, T. E., and Compton, W. A., "Radiation Pyrometer for Gas Turbine Buckets", prepared by Solar Division of International Harvester Company under contract F33615069-C-1374, for Air Force Flight Dynamics Laboratory, Air Force Systems Command, Wright-Patterson Air Force Base, Ohio, Technical Report AFFDL-TR-70-75 (June 1970).

3. Forsyth, W. E., "Optical pyrometry", Temperature, Its Measurement and Control in Science and Industry, New York: Reinhold, p. 1115 (1941).

4. Barber, R. and Land, T., "The Place of Photovoltaic Detectors in Industrial Pyrometry", Temperature, Its Measurement and Control in Science and Industry, Part II, New York: Reinhold, p. 391 (1962). 